Portland State University

PDXScholar

5-9-1996

\title{
Intervention History of Children with Slow Expressive Language Development
}

Kathleen Belfiore

Portland State University

Follow this and additional works at: https://pdxscholar.library.pdx.edu/open_access_etds

Part of the Speech and Rhetorical Studies Commons

Let us know how access to this document benefits you.

\section{Recommended Citation}

Belfiore, Kathleen, "Intervention History of Children with Slow Expressive Language Development" (1996). Dissertations and Theses. Paper 4944.

https://doi.org/10.15760/etd.6820

This Thesis is brought to you for free and open access. It has been accepted for inclusion in Dissertations and Theses by an authorized administrator of PDXScholar. Please contact us if we can make this document more accessible: pdxscholar@pdx.edu. 


\section{THESIS APPROVAL}

The abstract and thesis of Kathleen Belfiore for the Master of Science in Speech

Communication: Speech and Hearing Science were presented May 9, 1996, and accepted by the thesis committee and the department.

COMMITTEE APPROVALS:

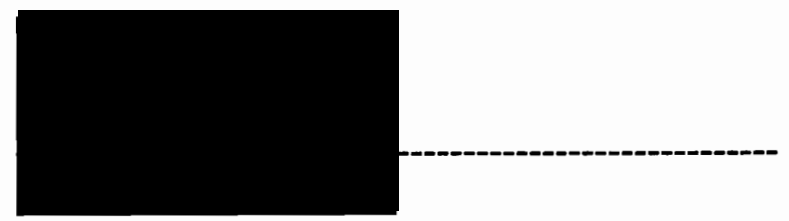

Dr. Rhea Paul, Chair

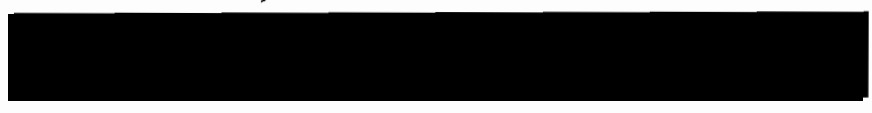

Dr. Lisa Letcher-Glembo

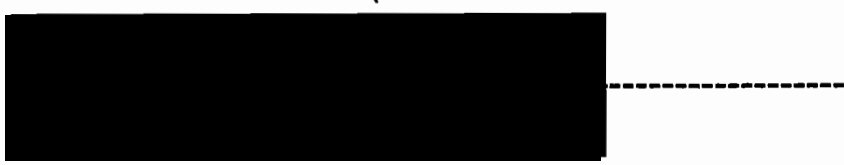

Dr. Joel Arick

Representative of the Office of Graduate Studies

DEPARTMENT APPROVAL:

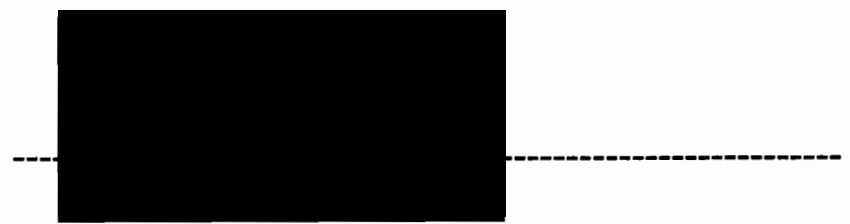

Dr. Rhea Paul, Acting Chair

Department of Speech Communication

ACCEPTED FOR PORTLAND STATE UNIVERSITY BY THE LIBRARY

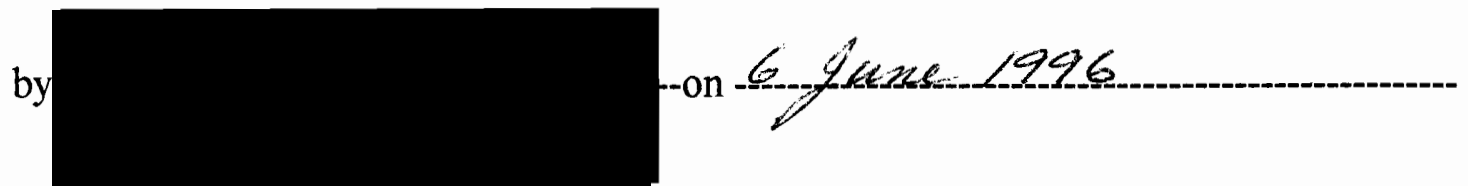




\begin{abstract}
An abstract of the thesis of Kathleen Belfiore for the Master of Science in Speech Communication: Speech and Hearing Science presented May 9, 1996.
\end{abstract}

Title: Intervention History of Children with Slow Expressive Language Development

Children who are identified with slow expressive language development (SELD) around the age of two are producing less than fifty intelligible words or no two word phrases. Current research suggests that some children with SELD outgrow their delay while others continue to develop long term language difficulties. The literature shows varied findings of short term recovery but long term deficits, and shifts in the specific expressive language deficits as the child with SELD matures and encounters increased language demands. Suggestions are found for a mix of monitoring and early intervention, in step with signs of readiness and dynamic assessments, to facilitate improved performance and hasten development, particularly in the areas of metalinguistics and narratives.

This study attempted to support the recommendation of early intervention, particularly for those children with an initial greater severity levels of expressive communication delay at the age of two. The 24 male and seven female SELD subjects 
were part of the Portland Language Development Project, a longitudinal study. Intake was at two years, and placement in the Intervention $(R x)$ or No Intervention (No $R x$ ) group was a result of follow-up information gathered from parents regarding enrollment in any early intervention services before the age of four. Using mean Developmental Sentence Scores (DSS) for four outcome points, t-tests determined that no significant differences existed in the improvement of language production between the $\mathrm{Rx}$ and No $\mathrm{Rx}$ groups. Secondly, t-tests showed no significant differences in the two group's initial severity levels, using the Expressive Communication sub-domain of the Vineland Adaptive Behavior Scale (VABS), as the measure of severity at intake.

A non-significant trend of consistently higher actual mean DSS scores across all outcome points, and an actual lower mean Expressive Communication score on the VABS at intake was noted for the Rx group. A significant difference was found in the mean intake ages of the two groups, with older toddlers falling into the $\mathrm{Rx}$ group.

Research and clinical implications are discussed, including attention to the length, type and content of very early intervention services, effective initial and followup assessments, and factors that favor recommending early intervention 
INTER VENTION HISTORY OF CHILDREN WITH

SLOW EXPRESSIVE LANGUAGE DEVELOPMENT

by

KATHLEEN BELFIORE

a thesis submitted in partial fulfillment of the requirements for the degree of

\author{
MASTER OF SCIENCE \\ in \\ SPEECH COMMUNICTION: \\ SPEECH AND HEARING SCIENCE
}

Portland State University

1996 


\section{ACKNOWLEDGEMENTS}

I wish to thank Dr. Rhea Paul for her guidance and assistance in this project. I am also grateful to my other Thesis Committee members, Dr. Lisa Letcher-Glembo and Dr. Joel Arick, for their valued input and contributions.

My deepest appreciation goes to my children, Shelyea, Guy, and Felice, for their love and constant caring support. A special thanks to my daughter, Felice, for her immeasurable help with data spreadsheets and rescue efforts during episodes of "computer frustration".

And to my friends and peers at Portland State University who helped me problem solve, listened to my complaints and celebrated with me after it all, I say "Thanks for helping to make it happen." 
PAGE

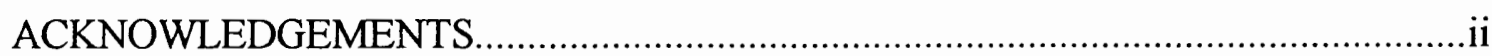

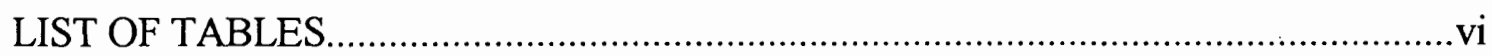

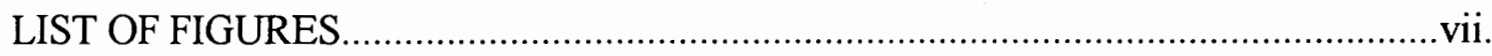

CHAPTER

I INTRODUCTION

Statement of Purpose

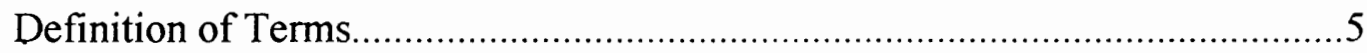

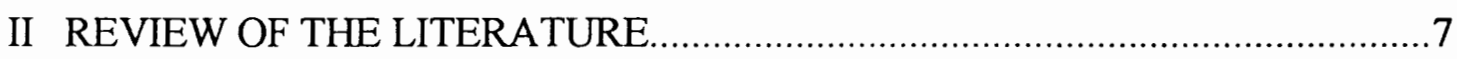

Normal Expressive Language Development.................................................

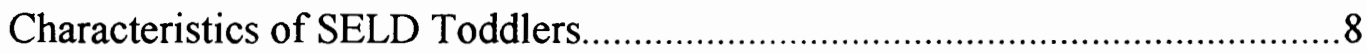

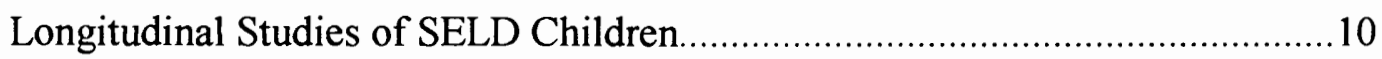

Predictive Factors for Continued Deficits

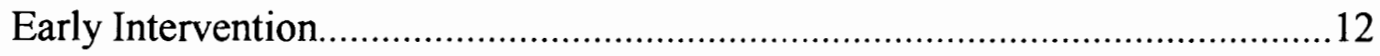

Facilitative Purpose of Early Intervention

Effectiveness of Early Intervention for SELD Toddlers

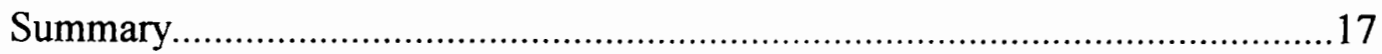

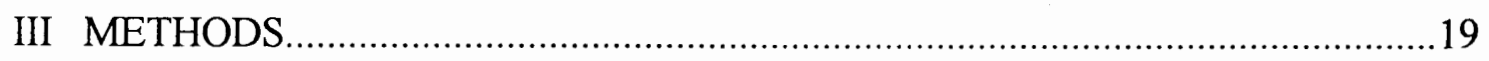

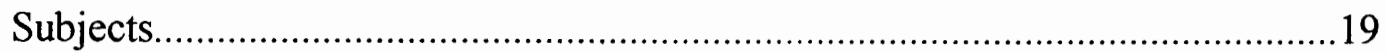

Subject Recruitment

Subject Description at Intake 
Procedures

Severity Level at Intake as Indexed by the Vineland Adaptive

Behavior Scales (VABS)

Follow-up Assessment at Pre-kindergarten, Kindergarten, First and Second Grade

Intervention History Reported at Age Four

Instrumentation.

The Vineland Adaptive Behavior Scales (VABS)

Developmental Sentence Score (DSS)

Reliability of Transcripton and DSS Scoring

Data Analysis.

Research Design One

Statistical Analysis

Research Design Two

Statisitical Analysis

IV RESULTS AND DISCUSSION

Results

DSS Outcomes at Four Points of Time

Severity Level Differences

Discussion.

Normalization of Outcomes Regardless of Intervention

Other Possible Contributing Factors

Pattern of Improvement

Intital Severity and Early Intervention

Severity and Age Range

Amount of Needed Improvement

V SUMMARY AND IMPLICATIONS 
Implications. 45

Research

Clinical

REFERENCES.

.51

APPENDICES

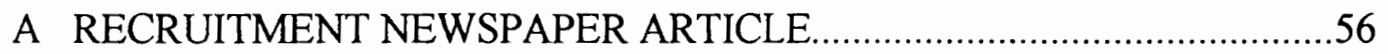

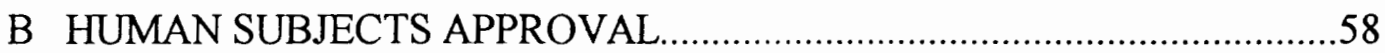

C LANGUAGE DEVELOPMENT SURVEY WORD LIST ..............................60

D ASSESSMENT INSTRUMENTS: BASELINE (AGE 2).............................62

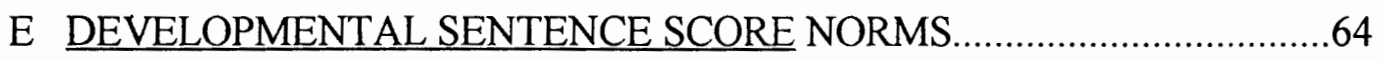

F DEVELOPMENTAL SENTENCE SCORES FOR RX AND NO Rx GROUPS AT PRE-KINDERGARTEN (AGE FOUR), KINDERGARTEN, FIRST GRADE, AND SECOND GRADE .66

F EXPRESSIVE COMMUNICATION SCORES OF THE VINELAND ADAPTIVE BEHAVIOR SCALES ADMINISTERED AT AGE TWO FOR Rx AND NO Rx GROUPS. .68 


\section{LIST OF TABLES}

TABLE

PAGE

1 Number of SELD Subjects Per Year 19

2 Demographics of SELD Children in Present Study. 21

3 Early Intervention History Before the Age of Four 31

4 Means, Standard Deviations, ț-test Values and Significance Levels

for Developmental Sentence Scores at Four Assessment Points. 32

5 Means, Standard Deviations, t-test Values and Significance Levels for the Expressive Communication Sub-domain of the Vineland Adaptive Behavior Scales at Intake. 
vii

\section{LIST OF FIGURES}

FIGURE

PAGE

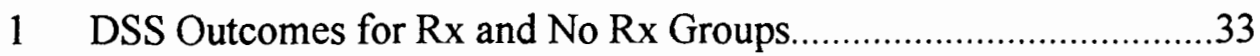

2 Mean DSS for Rx and No Rx Groups at Four Outcome Points.........38 


\section{CHAPTER I}

\section{INTRODUCTION}

Children at the age of two who appear normal in all aspects of development, but who are expressing fewer than fifty words or no two word combinations, are characterized as late talkers (Paul, 1991a). These children can be puzzling for the speech-language pathologist attempting to counsel parents who are concerned about the need for very early intervention. Research indicates that older preschoolers who have a language delay show continued deficits across various domains of language (Catts, 1993; Rescorla and Schwartz, 1990; Paul, 1995). Not as much is known about the prognosis for toddlers who are slow to talk, or about the effectiveness of very early intervention. Frequently, a "wait and see" approach is recommended, and some researchers support the theory that most expressive language delay will be spontaneously outgrown by the age of five and a half (Bishop and Edmundson, 1987; Whitehurst, Fishchel, Lonigan, Valdez-Menchaca, Arnold, and Smith, 1991)

However, there are some toddlers for whom the early expressive delay indicates future difficulties in language, particularly when faced with increased academic demands. It may appear that slow expressive language is the symptom of a specific delay at age two, but difficulties with phonological awareness, pragmatics, or syntax may be symptoms of the same impairment, at later stages of development. 


\section{STATEMENT OF PURPOSE}

The first purpose of this study is to focus on the efficacy of very early intervention services received by a specific population before the age of four, in order to answer the question, "Does very early speech and language intervention before the age of four result in significant differences in language production at four outcome points: prekindergarten (four years), kindergarten, first grade and second grade?". Specifically, the study will focus on a group of middle class children identified at the age of two as late talkers on the Language Development Survey (LDS), a parent checklist of early vocabulary. The Developmental Sentence Score (DSS), a norm referenced scale that measures syntactic complexity in children's spontaneous expressive language, will provide longitudinal outcome data. The late talkers will be referred to as children with slow expressive language development (SELD), and the outcomes for those children with SELD who received early intervention ( $R x$ group) will be compared to the outcomes of the SELD group who did not receive early intervention (No $\mathrm{Rx}$ group).

As an extension of the first purpose, the second purpose of this study is to determine if there is a relationship between initial severity of delay and subsequent enrollment in early intervention services before the age of four. Studies such as Bishop and Edmundson (1987) indicate a relationship exists between severity of language impairment and outcomes for children with specific expressive language delay. They also suggest that treatment is more likely to be given to children with the more severe impairments and theorize that severely involved children would have done even more 
poorly had they not received any treatment. The effects of very early intervention may be overshadowed by the range of initial severity levels found in expressive language. The question of initial severity differences between the $\mathrm{Rx}$ and No $\mathrm{Rx}$ groups may help further define children with SELD, and indicate initial severity as a factor for consideration when recommending early intervention. Additionally, the outcomes examined for the first part of this study relate to initial severity in that SELD children with the largest deficits in expressive communication must show a greater amount of change and improvement in performance to reach average levels of language production.

The research question asks "Were the children identified as having greater expressive language delays enrolled in very early intervention services, whereas participation in intervention was not pursued for those children identified as less delayed?". Children identified at approximately age two as late talkers, by use of the LDS, will be assessed at intake by administering the Vineland Adaptive Behavior Scale (VABS), a standardized, structured parent interview measure (Sparrow, Balla, and Cicchetti, 1984). One sub-domain of the VABS, the Expressive Communication Score, which is highly correlated to direct measures of language use, will be the data examined to determine if there is a significant difference of severity of delay between the $\mathrm{Rx}$ and No Rx groups of children with SELD. The following research hypotheses are stated for this study:

1. It is hypothesized that there will be significant differences in (a) prekindergarten (age four) DSS scores, (b) kindergarten DSS scores, (c) first grade DSS scores, or (d) second grade DSS scores, between two groups of late talking children, 
dependent on receiving or not receiving intervention services before the age of four.

2. It is hypothesized that there will be significant differences in the Expressive Communication score of the Vineland Adaptive Behavior Scales at intake (age two), between two groups of late talking children, dependent on receiving or not receiving intervention services before the age of four.

The null hypotheses are:

1. It is hypothesized that there will not be significant differences in DSS scores for late talking children at (a) pre-kindergarten (age four), (b) kindergarten, (c) first grade, nor (d) second grade, regardless of receiving or not receiving intervention before the age of four.

2. It is hypothesized that there will not be significant differences in the Expressive Communication score of the VABS for late talking children at intake, (age two), regardless of receiving or not receiving intervention before the age of four. 


\section{DEFINITION OF TERMS}

Developmental Sentence Score (DSS) (Lee 1974): A method of quantifying syntactic complexity in children's spontaneous utterances which contain a subjectpredicate relationship. Utterances are scored for eight grammatical and syntactical categories according to test criteria, with scores weighted by developmental level, and norms given for ages two to seven.

Efficacy of Intervention: When change in the knowledge of language and the ability to use language occurs due to treament. The change is at a faster rate or a higher, more advanced level than the change that occurs due to other, natural factors or extraneous variables.

History of Intervention ( $\mathrm{Rx})$ : Category for children who have received some language intervention before the age of four, as indicated by their parent on a questionnaire.

Language Development Survey (LDS): A highly reliable and valid vocabulary checklist completed by parents and designed for use as a screening tool for the identification of language delay in two year old children.

Late Talkers: Children who, according to parent report on the LDS, are expressing fewer than fifty words or no two word combinations by the age of two, but who are similar to their normally speaking peers in terms of nonverbal cognition.

Readiness: The observed, immediate potential for change when a child is most likely to best benefit from intervention. When the prerequisites for a particular behavior 
exist, and experience or instruction serves to induce or facilitate the emergence of the behavior.

Slow Expressive Language Development (SELD): When children produce fewer than 10 intelligible words at 18 to 23 months of age or fewer than 50 words or no twoword combinations by 24 to 34 months of age. Children with SELD are also referred to as late talkers.

Very Early Language Intervention: Group or individual treatment sessions, voluntarily obtained by parents before their child reached the age of four, varying from one half hour to three hours per week, and with a variable duration of one to 24 months. Vineland Adaptive Behavior Scales (VABS): a norm-referenced, structured parent report, measuring four domains: Communication (receptive and expressive language); Daily Living Skills ( self-care activities of eating, dressing, washing, etc..); Socialization (interpersonal relations, play and leisure); and Motor Skills (gross and fine coordination). The four domains are summed together to obtain an Adaptive Behavior Composite. The Expressive Communication score, the focus of this study, is specifically shown to correlate with direct measures of language use.

Vocabulary burst: a developmental stage of rapid growth in the number of new words used. 


\section{CHAPTER II}

\section{REVIEW OF THE LITERATURE}

Early identification of expressive language delay is an important and challenging task for speech-language pathologists, and has been the focus of research in recent years (Thal and Tobias, 1994, Paul, 1991a and b). A longitudinal study of toddlers with slow expressive language development (SELD) allows a look at variables, over time, which may be potential predictors of continued delay. Longitudinal studies show that many SELD children achieve normal levels of language proficiency by the age of five and a half(Bishop and Edmundson, 1987; Whitehurst, et al., 1991), while longer term outcomes may be much less favorable (Aram, Ekelman and Nation, 1984, Paul, 1991). In other words, both recovery from language problems and persistence of language problems may occur at different times in the SELD child's development (Scarborough and Dobrich, 1990). For SELD children, intervention before the age of four may accomplish facilitation, and minimize the long term effects of the delay (Paul, 1995).

\section{Normal Expressive Language Development}

Infants around 9 or 10 months begin to demonstrate expression with vocal and gestural modes. A change occurs around 12 months, when words are added to gestures and vocalizations. Between 18 and 20 months there is an increase in the rate of expressive vocabulary development, as some children experience a "vocabulary burst" 
(Thal and Tobias, 1994). Combining words into simple two word sentences most often accompanies that vocabulary burst. Miller (1981) found 24 month old children to be using equal numbers of one word and two word constructions. Stoel-Gammon (1987) showed speech samples for toddlers at 24 months included a variety of syllable shapes, and most expressed two syllable words. Although there is variability in vocabulary size, Fensen et al (as cited in Weismer, Murray-Branch and Miller, 1993) reports about 110 words in the vocabulary by 18 months, 312 words by 24 months, and 546 words by 30 months. Variation in the average vocabulary size decreases as children mature.

\section{Characteristics of SELD Toddlers}

The natural history of SELD toddlers shows that families do not generally have concerns for their children's development in the first two years of life. Not only are intentions to communicate indicated by vocalizations and gestures, but studies by Thal and Tobias (1994) suggest that SELD toddlers use more communicative gestures than normal controls. During the pre-kindergarten period, they give the impression of being normal, smart children, who somehow failed to learn to talk at the usual developmental stage. Scores on nonverbal IQ tests will typically fall in the normal range. There are more male than female children demonstrating SELD, with the literature commonly reporting a three or four to one ratio (Paul, 1992; Thal and Tobias, 1994; Olswang and Bain, 1994).

SELD children are distinguishable on the basis of their expressive language skills 
relative to other areas of development (Weismer, Murray-Branch and Miller, 1993).

Rescorla (1989) supports the view that language delay is identifiable by the age of 24 months, when developmental norms indicate at least 50 words are available in the expressive lexicon, as well as some two to three word combinations. A child who is not meeting this minimum production norm is considerably delayed in expressive language. Rescorla developed an instrument to be used with children as young as 18 months to efficiently identify expressive language delay in toddlers. The Language Development Survey (LDS) is based on the premise that a detailed parental report is a reliable and valid method to assess the very young child's productions (Soriano, Paul and Cohen, 1988). The LDS asks parents to check which of the 300 listed words the child actually uses, and to give examples of the child's sentences (see Appendix C). If the child reportedly uses less than 50 words, or does not use two words in combination, an expressive language delay is identified. Rescorla (1989) indicated that 10 to $14 \%$ of middle-class children sampled with the LDS fail to meet these criteria by their second birthday. The LDS has been reported to show excellent reliability, validity, sensitivity and specificity for identifying toddlers with expressive language delay (Rescorla, 1989).

Paul (1991b) describes the characteristics of toddlers with SELD as late talkers of normal intelligence who show a small expressive vocabulary. SELD toddlers do not perform as well as their normally developing peers on measures of socialization skills, and are reported by parents to show significantly more problem behaviors. Paul also reports that SELD toddlers show less maturity in phonological production than toddlers with a normal expressive vocabulary size. 
Longitudinal Studies of SELD Children

Rescorla and Schwartz (1990) followed 25 SELD two year old boys. By the age of three to four, few were reported to be speaking in completely fluent or syntactically complex, morphologically correct sentences. Half of the boys still had very limited expressive language, were speaking in short, telegraphic sentences, and many of them had moderately severe articulation disorders. Similar results in follow-up studies of SELD toddlers (Rescorla and Schwartz, 1990; Paul, 1993; Thal 1991) show approximately half reach the age of three with persistent language difficulties. Paul followed 28 SELD toddlers to age three, finding that although expressive vocabulary size begins to move into a normal range, other expressive skills, such as sentence structure and articulation remain delayed. Paul and Smith (1993) looked at the same children at four years of age and found that narrative skills, a predictor of school success, were significantly less developed than those of their peers. A large portion of three and four year old SELD subjects also retained articulation deficits. An additional study, using the same subjects, suggests that even after communication skills moved within the normal range, social skills often continued to be disrupted. (Paul, Spangle-Looney and Dahm, 1991).

In a study by Bishop and Edmundson (1987), $44 \%$ of the 87 subjects who had expressive language delay at four showed normal levels of language skill by five and a half. Whitehurst, et al. (1991) draws the conclusion that children identified at two as slow talkers (SELD) manifest delay in expressive vocabulary, but have caught up by age 
five or six, although Whitehurst's study does not measure pragmatic or syntactic development.

Scarborough and Dobrich (1990) agree that children with a history of SELD appear to recover the deficit around the age of five, but they refer to this as "illusory recovery", and partially credit the slowing of their peers' development. Their study followed four children who presented severe and broad impairments in syntactic, phonological, and lexical production at two and a half years of age. Over time, the deficits appeared more selective, and normal or near normal speech was produced by age five. However, three years later, three of the four were severely reading disabled. They suggest that the development of normal language progresses in step-wise growth patterns, with spurts around the ages of three and six. When delayed children appear to "catch up", normally developing peers may be at a temporary plateau. According to the model of short term recovery and long term persistence, differences are expected to reemerge once normally developing children undergo the next growth spurt. SELD subjects show variability in the severity and scope of deficits over time, therefore improvements in preschool abilities do not necessary indicate future school achievement.

\section{Predictive Factors for Continued Deficits}

Thal, Tobias, and Morrison (1991) reported two possible predictive factors of continued language problems in toddlers as young as 18 months, based on a follow-up study of SELD children. The factors were a delay in vocabulary comprehension and poor production of symbolic gestures in familiar scripts.

Weighing risk factors, such as medical history, family and social factors, and 
known developmental disorders, is recommended by Paul (1993) when assigning priority for intervention and predicting continued deficits. Based on data from a longitudinal study of 37 late-talking toddlers who demonstrated expressive language delay without additional risk issues, Paul shows that two predictive factors emerge. The first predictive factor, the age of the child at intake, is similar to findings by Rescorla and Schwartz (1990). The longer the child continues to produce less than 50 words, the more likely they will have long term deficits. The second factor is gender. Although the prevalence of SELD in girls is less than in boys, the chances of spontaneous recovery during the preschool period for girls appears to be less.

Bishop and Edmundson (1987) report that they were able to predict the correct outcome (good or bad) for $90 \%$ of the 87 language impaired subjects on the basis of a one-hour language assessment administered at the age of four. Bishop and Edmundson concluded that first, the more types of impaired language functions a child has, the more likely the child will have continued language impairments, and second, prediction of poorer outcomes are reliable for four year old children who are unable to retell sequential events of a story with the aid of a picture.

\section{Early Intervention}

A mandate exists to provide evaluation and treatment for children in the birth to three year age group with the amendment to Public Law 99-457. Intervention is defined as intensive, focused stimulation, provided individually or in groups, to work on the 
improvement of particular aspects of language (Olswang and Bain, 1991). The need for facilitative intervention for language delayed toddlers will be encountered more frequently if SELD is considered an early warning sign of future difficulty in phonological awareness, sequencing, narratives, writing, and other residual speech and language problems. For SELD children, the learning deficit may remain, although the symptoms may change over time. The task is to identify language behaviors that are missing, and attempt to stimulate the growth of those behaviors along with the underlying linguistic rules (Paul, 1993).

\section{Facilitative Purpose of Early Intervention}

The focused experience of intervention can alter behavioral development in three general ways, as Gotlieb (1981) proposed. First, the facilitative experience can accelerate learning by effecting an undeveloped or partially developed behavior, hastening the end point that would have been attained in much slower, unassisted development. Secondly, induction is responsible when a behavior is totally missing, although the prerequisites may be present, and the intensive and specific stimulation of intervention produces the behavior. Reaching the result would not have occurred without the focused intervention, seen as an extra boost of experience. Finally, intervention can be viewed in terms of maintenance, to help an immature system keep functioning, with intervention preserving what specific abilities have already developed, guarding against deterioration of basic skills.

Olswang and Bain (1991) indicate that for children with expressive language delays, intervention for the goal of maintenance does not readily apply. The SELD 
population is ready to move on with further language acquisition, once a specific behavior or rule is learned, and maintenance of foundation skills is automatic. Facilitation is the term most commonly associated with intervention for children with SELD, and questions of intervention efficacy are raised when it appears that the child will eventually reach the same endpoint as those who do not receive the extra boost of intervention. Although the specific targeted skill, such as increased vocabulary, may be eventually achieved with or without intervention, other skills that coordinate developmentally with the target may also be delayed, such as metalinguistic knowledge, which is vitally important in later literacy development (Paul 1991). Social skills and self-esteem may be effected while communication skills are delayed, and important parent-child interactions may be limited. Olswang and Bain (1994) remark that intervention may appear to "merely" facilitate a faster rate because the limited way language status is measured in some research, which does not look at a dynamic assessment of the complexities of language skills expected to develop in the early school years.

\section{Effectiveness of Early Intervention for SELD Toddlers}

Early intervention for SELD entails complex decisions, as does planning and implementing language intervention at any age. It is difficult to objectively and completely show the effectiveness of that intervention. Fey and Cleave (1990) discuss methods for evaluating the efficacy of intervention that would help the clinician better understand their intervention outcomes and help with planning for future intervention. One method is based on the idea that intervention not only facilitates learning of 
individual language targets but also stimulates accelerated, spontaneous learning. The authors suggest a look at measurements of performance before and after "breaks" in treatment. A plateau or regression following the period of non-intervention would suggest a need for continued treatment, while progress over that time would indicate spontaneous learning and justify new goals.

Studies have demonstrated the effectiveness of treatment for preschoolers with expressive language impairments (Cole and Dale, 1988), but not much is known about the efficacy of intervention for late talking toddlers. Whitehurst and colleagues (1991) investigated specific gains in productive vocabulary in relationship to intervention for late talking toddlers. Intervention signaled a faster rate of gain in vocabulary for the toddlers, however, productive vocabulary at age five for those who received and did not receive intervention were reportedly similar. The study resulted in a statement that intervention was effective, but not important for toddlers.

Paul (1991 b) points out that Whitehurst's results may have been limited by the small range of language skills which were assessed. The underlying processes that disrupted the expressive language acquisition in SELD subjects may affect later academic learning skills. Olswang and Bain (1991) argue that even if the child with SELD catches up with peers, other interrelated skills, such as metalinguistic knowledge for literacy development or social-emotional development may be affected while the child is having early language problems. They also point out that intervention for SELD subjects may improve parent-child relations, and provide opportunities to develop small group interactive social skills, facilitating more than measurable language gains. 
Weismer, et al. (1994) summarizes that even if late talkers actually do catch up to their normal language peers by the end of the preschool period, early intervention is valuable as facilitative treatment, regulating maturation, hastening development, and improving performance.

The results of research by Olswang and Bain (1991) suggests that intervention is most effective at critical learning periods, defined by readiness and growth spurts, when the organizational process of language is more easily altered. They point out that the toddler may move in and out of intervention, responding to different treatment delivery models and intervention strategies. Long and Olswang (1996) address the issue of readiness to learn a new behavior, and point out that if readiness is evaluated through dynamic assessment, and found lacking, the child could be provided with indirect service such as a home-based program. A mixture of intervention and monitoring is suggested as the most effective approach, calling for ongoing data collection and evaluation.

Paul, Laszlo, and McFarland (1992) indicate that intervention may be justified for young preschoolers with SELD as a preventative measure, based on concern for potential school success. The focus of treatment, they report, should include a narrative and a metalinguistic component, facilitating the ability to tell simple stories and to manipulate and talk about words and parts of words.

Olswang and Bain (1994) discuss critical questions concerning ways to decide if treatment is responsible for significant, important change. Assuming that efficacy is based on data, they advocate looking at both behavioral, quantitative data and subjective, qualitative data. Gathering both kinds of data acknowledges complex variables that 
surround change. Children tend to change and improve as a result of both experience and simple maturation. Efficacy studies need to demonstrate that intervention is responsible for the change with supportive data to indicate a faster rate of change, the importance of the change to the client's well being, and a change in performance great enough to be recognized or generalized.

\section{Summary}

Research indicates that children identified as late talkers or children with SELD, may continue to have difficulties with expressive language during preschool, and may be at risk for future academic deficits. Longitudinal studies attempt to define predictors for continued deficits, and measure the outcomes for SELD children over time. Early intervention may be viewed as facilitation of expressive language skills for children at risk for future language and reading deficits as well as delay in social and academic development. There is limited research specifically related to the effects of very early intervention for toddlers with expressive language delay. This study will focus on quantitative data in the form of DSS outcomes for children identified by the LDS at age two as children with SELD, as they progress from age four through second grade. The efficacy of early intervention will be investigated by testing for significant differences between the group of children who received treatment before the age of four and the group of children who did not receive treatment. It will also describe the severity of the expressive delay, as measured qualitatively with the VABS at the time of intake, in 
relationship to procurement of treatment for the child before the age of four. 


\section{CHAPTER III}

\section{METHODS}

\section{Subjects}

The subjects for this study were drawn from those participating in the Portland Language Development Project (PLDP), a longitudinal study which looked at outcomes of early language delay. The PLDP involved both normal and late talkers, however, this study looks only at the late talking subjects, classifying them as toddlers with specific expressive language delay (SELD). There were 35 subjects classified as late talkers in the PLDP. For this study, 31 of these subjects constitute the longitudinal sample. They were selected because their data sets were complete for at least two of the four years of examined Developmental Sentence Scores (DSS). This study looks at the time span from age two to second grade, and although all subjects had an opportunity to participate each year, the number of subjects varied. (see Table 1)

Table 1

Number of SELD Subjects at Intake and Follow-up Assessment Points

Subjects Intake Pre-kindergarten Kindergarten First Grade Second Grade

\begin{tabular}{lrrrrr} 
Boys & 24 & 24 & 21 & 20 & 22 \\
Girls & 7 & 7 & 6 & 7 & 7 \\
\hline
\end{tabular}




\section{Subject Recruitment}

The subjects were recruited for the PLDP through pediatric clinics, radio announcements, and an Oregonian newspaper article (see Appendix A). Application to the Human Subjects Research Review Committee was made for approval of the PLDP and this study, based on the PLDP data (see Appendix B). The parents of the 18 to 34 month old subjects provided written permission for participation and filled out a questionnaire, which included demographic information, questions regarding the number of different words the child expresses, and if words are combined to form short sentences.

\section{Subject Description at Intake}

Selected subjects, at the time of intake, were identified as either late talkers or normal talkers by use of the Language Developmental Survey (LDS) (Rescorla, 1989), a 300 word checklist and reporting form (see Appendix C). Children were considered to have slow expressive language development (SELD) if parents reported fewer than 50 words expressed at 20 months on the LDS. For the original PLDP, a group of normal talkers, whose parents indicated they produced more than 50 words at 20 months on the LDS, were also identified and matched to the late talkers on the basis of chronological age, race, birth order, and socioeconomic status (SES). SES was based on a Myers and Bean (1965) adaptation of Hollingshead's four-factor scale of social position, using a scale of 1 to 5 , with 1 being the highest SES and 5 the lowest. The mean SES was at the middle- to lower-middle class, and there were more non-Whites in the original PLDP normal subject group. For this study, the subjects are drawn only from the group of 
children identified as late talkers, or children with SELD. The demographics for these subject are outlined in Table 2 .

Table 2

Demographics of SELD Children Included in this Study

Subjects

n $\quad$ Mean Age

SES

Race

LDS Vocab

Boys

$24(77 \%)$

25.2

2.4

$96 \%$ White

20.48 words

Girls

$7(23 \%)$

24.8

3.2

$88 \%$ White

37.25 words

All subjects selected for participation in the original PLDP were given intensive assessments, including tests for adaptive behavior, receptive language, oral motor function and an audiological sound field screening at $25 \mathrm{~dB} \mathrm{HL}$. A complete list of the assessment instruments used for baseline evaluations at intake is found in Appendix D. To verify normal intellectual functioning, a psychologist administered the Bayley Scales of Infant Development (Bayley, 1969) and all subjects scored above 85. The subjects showed no known mental or physical impairments that might relate to delayed language or the ability to develop language. Assessment results were shared with parents, and for children with SELD, options of intervention were discussed. 
Procedures

Severity Level at Intake as Indexed by the Vineland Adaptive Behavior Scales(VABS)

The primary caregiver of each subject was interviewed at intake using the VABS at intake, following detailed guidelines and criteria for administering, scoring, and interpreting test results. The interview utilized general questions about the child's performance in the domains of: (a) communication, (b) daily living, (c) socialization and (d) motor skills, followed by further probes when needed. In the original PLDP, Paul, Spangle- Looney and Dahm (1991) reported significantly different scores between the control group and children with SELD in the communication and socialization domains of the VABS. The results of the 1991 study indicated that late talking toddlers are likely to be impaired not only in expression, but also language reception and socialization skills. For this study, only the Expressive Communication sub domain is used as an indicator of the level of communication deficit severity. The expressive communication scores correlate closely with Mean Length of Utterance measurements, and correlate highly with the LDS scores (Rescorla, 1989). The VABS is one of the few ways to evaluate the severity of SELD in toddlers, and is closely related to direct measures of productive language (Soriono, Paul, and Cohen, 1988). The procedure for this study compares the severity levels as indicated by the Expressive Communication Score between the children with SELD who have a history of early intervention and the SELD children who did not participate in early intervention. 


\section{Speech Sampling}

During each follow-up evaluation for SELD subjects, assessment included spontaneous speech samples, obtained by audiotaping approximately 15 minutes of free play interaction between the parent and child. A Sony BM-80 Dictator/Transcriber tape recorder with an Electret Condenser solar ECM-D8 microphone was placed near the carpeted play area. Parents were given a selection of toys and manipulatives and were told to play with their child as they naturally would at home. The second grade followup speech sample was obtained using an interview format with the child. Follow-up Assessment at Pre-kindergarten, Kindergarten, First, and Second Grade

Follow-up procedures included a variety of age appropriate standard measures of expressive and receptive language, adaptive behavior, and phonological productivity, administered by trained graduate students in the Speech and Hearing Sciences Program at Portland State University. In addition, a free speech sample collected while the subject was engaged in unstructured play with a parent was recorded and later scored for syntactical development by use of the Developmental Sentence Score (DSS)(Lee, 1974). The DSS was chosen as the measure of interest for this study because it is a direct measure of syntactical ability, sensitive to actual expressive communication skills. Although the VABS continued to be a part of the follow-up protocol, it was no longer necessary to rely on parent interview regarding the subject's spontaneous speech. DSS outcomes falling at or above the tenth percentile for a given age (see Appendix E) designate normal development, and scores below the tenth percentile indicate a delay. DSS scores recorded at pre-kindergarten (four years of age), kindergarten, first and 
second grade follow-up assessments were collected for each subject.

Intervention History Reported at Age Four

Children participating in the project were seen for yearly follow-up assessments of language and language-related skills. When the SELD subjects were approximately four years old, as part of the protocol, parents were asked to complete a questionnaire requesting the following information: (a) if the child received any special education or speech therapy, (b) if they did receive therapy, what agency provided the program, was it an individual or group program, and how many hours a week did the child participate (c) if it was the only program, and if not, (d) how many others had been used, and (e) how long the child had been enrolled in therapy including all programs. This study describes the information gathered on the parent questionnaire regarding the history of intervention for SELD children prior to the age of four. The information found on this parent questionnaire is the basis for dividing the subjects with SELD into two groups: those who received very early intervention before the age of four ( $R x$ group), and those who did not receive very early intervention services (No $\mathrm{Rx}$ group). 
Instrumentation

\section{The Vineland Adaptive Behavior Scales (VABS)}

The VABS (Sparrow, et. al, 1984) which assess personal and social adaptability by means of a scorable structured interview, was conducted by a trained SpeechLanguage Pathology graduate student at intake. The Vineland Adaptive Behavior Scales (VABS) assesses four domains: communication, daily living skills, socialization, and motor skills. Each domain is arranged in developmental order, describing behaviors from birth to age 18. The VABS is presented to the subject's parent or the primary caregiver in an interview style. Open-ended questions are asked in order from general to specific, and focus is on what the subject does, rather than does not, do. The results are an accurate description of each subjects' communication and socialization skills. The VABS was developed over six years with subjects chosen to match the United States Census figures for the 1980 population. Pilot tests of the VABS were shown to assess adaptive behavior, which is defined as "the performance of daily activities required for personal and social sufficiency" (Sparrow et al., 1984). Split-half reliability coefficients for the composite (total) score ranged from .89 to .90 , and for test-retest reliability, .80 to 90. Measures of construct, content, and criterion related validity were also strong. Social competency scores can be compared to intellectual development on such tests as the Bayley Mental and Motor Scales, and the Revised Stanford-Binet. The VABS can be used to pinpoint strengths and weaknesses and develop individual treatment programs (Sparrow it al., 1984) For this study, a 12 percent reliability sample showed a 99\% 
degree of interrater agreement for scoring the VABS.

\section{Developmental Sentence Score(DSS)}

Speech samples were analyzed using the DSS, a norm-referenced instrument that assesses expressive syntax and morphological development. Spontaneous speech utterances which contain both a subject and a predicate are scored with specific points, according to Lee's (1974) criteria related to stages of syntactical development. The syntactic categories scored are: (a) indefinite pronouns, (b) personal pronouns, (c)main and secondary verbs, (d) negatives, (e) conjunctions, (f) interrogative reversals, and (g)Wh-questions. Attempts at a syntactical category are noted, and a sentence point is awarded if the utterance is a correct adult sentence form. The DSS gives information on patterns of strengths and patterns of errors, as well as an overall score and percentile rank. The DSS was standardized on 200 middle class, Caucasian children age 2 to 6.11 . The internal consistency is . 71 and the split-half reliability is .73 (Lee, 1974).

\section{Reliability of Transcription and DSS Scoring}

Each year, following the administration of the DSS, a point-to-point comparison of words transcribed from $10 \%$ of the spontaneous speech samples was performed by an additional trained researcher who was directly involved in the PLDP and also present at the time of the language sampling. The number of transcribed words in agreement divided by the total words transcribed showed an agreement score for pre-kindergarten (age four), kindergarten, first and second grade of $97 \%, 89 \%, 95 \%$ and $92 \%$

respectively. Each year the spontaneous speech samples scored on the DSS were tested for inter-rater reliability by having two independent, trained graduate student raters score 
$10 \%$ of the speech samples, using a point-to-point comparison. The total number of syntactical category points in agreement by the two raters was divided by the total number of syntactical category points in agreement and disagreement, arriving at $92 \%$, $93 \%, 92 \%$ and $94 \%$ reliability at pre-kindergarten (age four), kindergarten, first and second grade respectively. 
Data Analysis

\section{Research Design One}

This study is a simple between-group design, involving one independent variable with two levels, and one dependent variable examined at four follow-up assessment points. The independent variable is the history of early intervention before the age of four. The two levels are the group of SELD toddlers who were reported by their parents to have received any individual or group intervention before the age of four $(\mathrm{Rx})$ and the group of SELD toddlers who were reported to have not received intervention before four (No $\mathrm{Rx}$ ). The dependent variable is the DSS score recorded at pre-kindergarten, (four years), kindergarten, first grade and second grade for the two groups.

\section{Statistical Analysis}

A group mean and standard deviation for the Developmental Sentence Scores are computed for each of the two groups ( $\mathrm{Rx}$ and No $\mathrm{Rx}$ ) at each of the outcome points (four years, kindergarten, first and second grade). A parametric two sample $\underline{t}$-test with a .05 level of significance is applied to determine if there are significant differences in DSS scores between the two groups, for each of the four points of time.

\section{Research Design Two}

This study is a simple between-group design, with early intervention history remaining the independent variable with two levels represented by the $\mathrm{Rx}$ and No Rx groups, as in Research Design One. The dependent variable is the Expressive Communication score of the Vineland Adaptive Behavior Scales, recorded at intake, for two year old subjects 
identified as slow talkers (SELD).

$\underline{\text { Statistical Analysis }}$

A group mean and standard deviation of scores recorded on the VABS, at intake, for the Rx and No Rx groups are computed. A two sample t test with a .05 alpha level is applied to the dependent variable of the Expressive Communication scores of the Vineland Adaptive Behavior Scales, recorded at age two, to determine if there is a significant difference in the initial severity level of the two groups. 


\title{
CHAPTER IV
}

\section{RESULTS AND DISCUSSION}

\author{
Results
}

There were two purposes of this study. The first purpose was to determine if there were significant differences in language production between groups of children with slow expressive language development (SELD) based on receiving ( $\mathrm{Rx}$ group) or not receiving intervention services (No $\mathrm{Rx}$ group) before the age of four. The Developmental Sentence Score(DSS) was the index of language production at four outcome points: pre-kindergarten, kindergarten, first grade and second grade. The research hypothesis stated that a significant difference would exist. Assuming that the $\mathrm{Rx}$ group showed higher scores than the No Rx group, the efficacy of early intervention would be supported.

The second purpose of the study was to determine if there were significant differences in the initial severity of expressive language delay between the group of children with SELD who received intervention services before the age of four and the group of children with SELD who did not receive intervention before four. The Expressive Communication score of the Vineland Adaptive Behavior Scale (VABS) was used as the index of initial severity, administered when the subjects were two years of age. The research hypothesis stated that a difference would exist. Assuming that the Rx group showed lower scores, the need and motivation for enrolling in intervention 
services would be underlined, along with the observation that the children with SELD who were more severely delayed would need to do more "catching up" to their normally developing peers, adding to the justification for enrollment in early intervention.

\section{Groups Based on Intervention History Data}

Two groups of children with SELD were defined, based on parent report of receiving or not receiving early intervention before the age of four. For the $\mathrm{Rx}$ group, which consisted of 12 out of 31 total subjects, the reported information included the type, location and length of intervention services, as is found in Table 3.

Table 3

Early Intervention History Before the Age of Four

\begin{tabular}{|c|c|c|c|c|c|c|}
\hline $\begin{array}{l}\text { Subject } \\
\text { Number }\end{array}$ & Agency & $\begin{array}{c}\text { Groupl } \\
\text { Individual }\end{array}$ & $\begin{array}{c}\text { Hours } \\
\text { per week }\end{array}$ & $\begin{array}{c}\text { Only Tx } \\
\text { Program? }\end{array}$ & $\begin{array}{c}\text { Total Other } \\
\text { Programs }\end{array}$ & $\begin{array}{c}\text { Duration- } \\
\text { All Programs }\end{array}$ \\
\hline 007 & Head Stant - PPS & 1 & $2: 00 /$ month & No & 3 & $24 \mathrm{Mo}$ \\
\hline 019 & PSU & 1 & 1:40/week & Yes & & $3 \mathrm{Mo}, 2 \mathrm{Wks}$ \\
\hline 085 & Private & 1 & :30/week & Yes & & $1 \mathrm{Mo}$ \\
\hline 091 & Beavercreek Elem. & G \& I & :40/week & Yes & & $24 \mathrm{Mo}$. \\
\hline 091 & Private & 1 & 1:00/week & No & 1 & $12 \mathrm{Mo}$ \\
\hline 093 & PSU & $G$ & 2:00/week & Yes & & Not Available \\
\hline 100 & Private & 1 & 1:00/week & Yes & & $14 \mathrm{Mo}$ \\
\hline 102 & PSU & 1 & Not Available & Yes & & $6 \mathrm{Mo}$ \\
\hline 103 & PSU & 1 & 1:40/week & Yes & & $2 \mathrm{Mo}$ \\
\hline 111 & PPS & $G$ & 1:40/week & Yes & & $3 \mathrm{Wks}$ \\
\hline 115 & Private \& PPS & $G \& 1$ & 2:00/week & No & 2 & $24 \mathrm{Mo}$ \\
\hline 119 & PSU & 1 & 3:00/week & Yes & & $2 \mathrm{Mo}$ \\
\hline
\end{tabular}

The data indicate that, by the age of four, 10 out of the 12 SELD subjects received individual treatment sessions ranging from one half hour per week to three hours per week (mean: one hour, 28 minutes per week). Five children particpated in individual sessions at Portland State University (PSU). Four children participated in group sessions offered by the Portland Public Schools (PPS). Private practice speech 
pathologists worked with four children. For all children in the Rx group, the duration of reported intervention services ranged from three weeks to two years, with the average being ten months, one week.

\section{DSS Outcomes for Four Points of Time}

The first question posed in this study was "Does very early speech and language intervention result in significant differences in language production at four follow-up assessment points: pre-kindergarten, kindergarten, first and second grade?" The subjects' Developmental Sentence Scores, a direct measure of syntax and morphology, were used to respond to this question, and the recorded data of raw DSS scores are presented in Appendix F. A two-sample t-test comparison showed that the means for the groups at each outcome point did not differ significantly $(p>.05)$. Results are indicated in Table 4 for each of the four follow-up assessment points.

Table 4

Means, Standard Deviations, t-test values, and Significance Levels for Developmental Sentence Scores at Four Assessment Points.

\begin{tabular}{|c|c|c|c|c|c|}
\hline Assessment Point & Rx Group & No Rx Group & Signi & ficance & \\
\hline $\begin{array}{l}\text { Pre-kindergarten } \\
\qquad n=31\end{array}$ & $\begin{array}{ll}\mathrm{M} & 5.90 \\
\mathrm{SD} & 1.46\end{array}$ & $\begin{array}{l}\text { M } 5.58 \\
\text { SD } 2.51\end{array}$ & $t=.54$ & $\mathrm{p}=.59$ & $29 \mathrm{df}$ \\
\hline $\begin{array}{c}\text { Kindergarten } \\
n=27\end{array}$ & $\begin{array}{l}M 7.03 \\
\text { SD } 2.79\end{array}$ & $\begin{array}{c}\mathrm{M} 6.55 \\
\mathrm{SD} 3.28\end{array}$ & $t=.76$ & $p=.46$ & $25 \mathrm{df}$ \\
\hline $\begin{array}{l}\text { First Grade } \\
\qquad n=27\end{array}$ & $\begin{array}{l}M \quad 7.04 \\
\text { SD } 2.92\end{array}$ & $\begin{array}{l}M \quad 6.69 \\
\text { SD } 2.92\end{array}$ & $\mathrm{t}=.80$ & $p=.43$ & $25 \mathrm{df}$ \\
\hline $\begin{array}{l}\text { Second Grade } \\
\qquad n=29\end{array}$ & $\begin{array}{ll}M & 9.91 \\
\text { SD } & 1.94\end{array}$ & $\begin{array}{l}\text { M } 8.58 \\
\text { SD } 3.64\end{array}$ & $t=.60$ & $p=.55$ & $27 \mathrm{df}$ \\
\hline
\end{tabular}


Although the Rx group showed a higher DSS mean than the No Rx group at the first outcome point of pre-kindergarten, and continued that trend through the kindergarten, first, and second grade assessment points, the differences between the groups were not significant, indicating that the null hypothesis cannot be rejected. Figure 1 is a line graph representing the mean DSS scores for the Rx and No Rx groups at the four outcome points.

Figure 1

DSS Outcomes for Rx and No Rx Groups

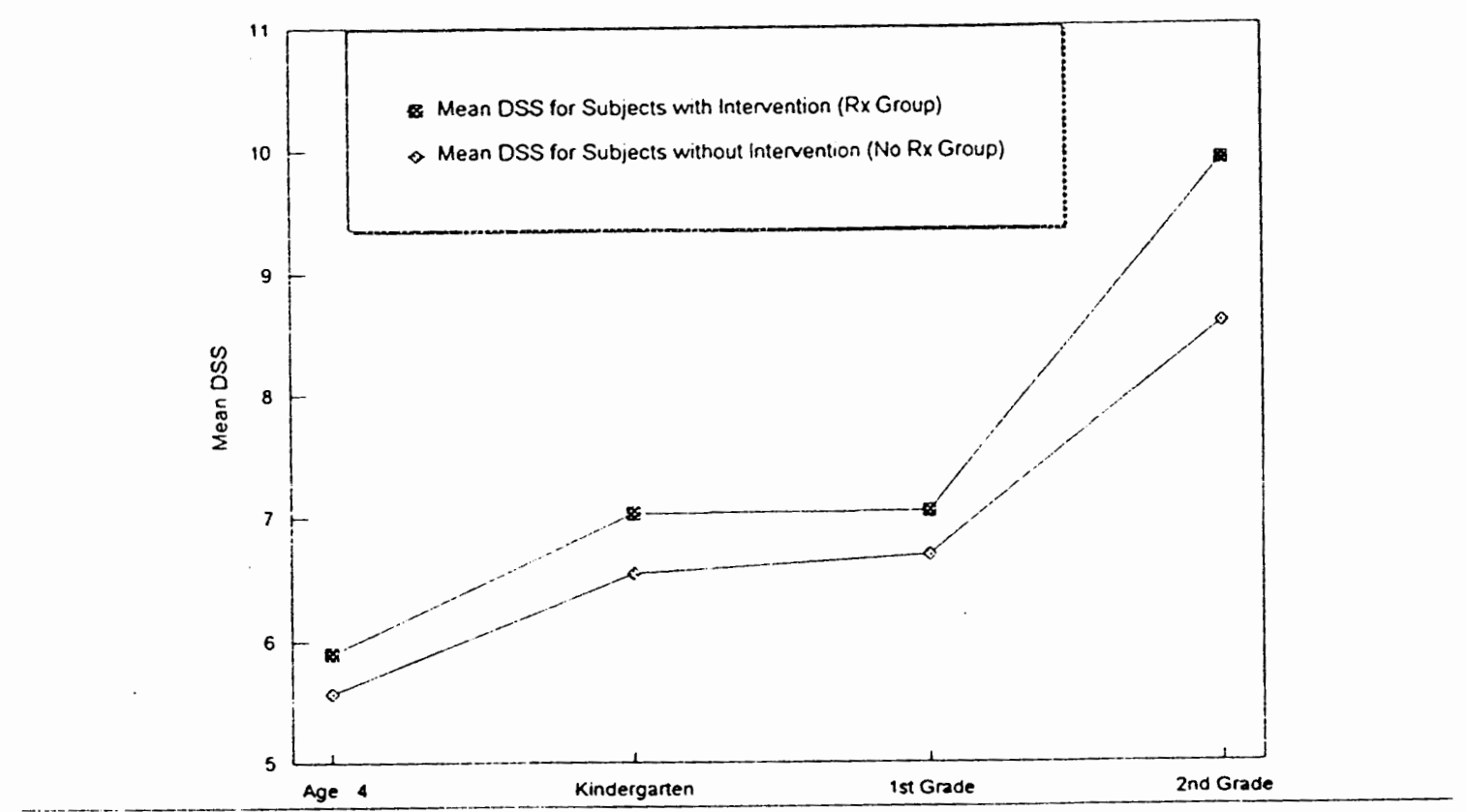

Mean DSS scores for the Rx and No Rx groups of children with SELD show similar amounts of change between pre-kindergarten and kindergarten, improving by 1.13 points for the $\mathrm{Rx}$ group and .97 points for the No Rx. group. Score improvement for both groups leveled off between kindergarten and first grade, improving by .01 and 
.14 points for the $\mathrm{Rx}$ and No $\mathrm{Rx}$ group respectively. A greater amount of positive change was shown for the $\mathrm{Rx}$ group between the first and second grade follow-up with a 2.82 increase in the mean for the $\mathrm{Rx}$ group, compared to 1.89 for the No $\mathrm{Rx}$ group. Additional research is needed to further explain the amount of change seen in the two groups over time, particularly betwee the first and second grade follow-up assessments.

\section{Severity Level Differences}

The second question asked in this study was "Are there significant differences in the initial severity level of the two groups of late talkers?" The Expressive Communication sub-domain of the Vineland Adaptive Behavior Scales (VABS), administered at intake, (age two) was used as the index of severity of slow expressive language development. A two tailed t test was applied to the mean scores of the $\mathrm{Rx}$ and No Rx groups. The Expressive Communication raw scores and the chronological age of each subject are displayed in Appendix G. The group means and standard deviations, along with the statisical analysis information is displayed in Table 5.

Table 5

Means, Standard Deviations, t-test Values and Significance Levels for the Expressive Communication Sub-domain of the Vineland Adaptive Behavior Scales at Intake.

\begin{tabular}{ccccc}
$\begin{array}{c}\text { Rx Group } \\
\mathrm{n}=12\end{array}$ & $\begin{array}{c}\text { No Rx Group } \\
\mathrm{n}=19\end{array}$ & \multicolumn{2}{l}{ Significance } \\
\hline M 13.91 & M 14.05 & $\mathrm{t}=.13$ & $\mathrm{p}=.41$ & $29 \mathrm{df}$ \\
SD 1.78 & SD 3.11 & & & \\
\hline
\end{tabular}

The mean Expressive Communication raw score for the Rx group (13.91) was lower than the mean Expressive Communication score for the No Rx group (14.05), 
which indicated that the Rx group of SELD children, at age two, showed a somewhat greater deficit. However, the $\underline{t}$ test indicated that the difference was not significant. The null hypothesis cannot be rejected, and the answer to the research question is that severity of expressive delay at age two is not a significant indicator of being in the $\mathrm{Rx}$ subject group, or receiving very early intervention services. 
Discussion

\section{Normalization of Outcomes Regardless of Intervention}

One purpose of this study was to determine if there were significant differences in language performance, across time, between the $\mathrm{Rx}$ and No $\mathrm{Rx}$ groups of children with SELD. No significant differences were found, suggesting that early intervention before the age of four does not significantly effect the outcomes of language production at subsequent points of pre-kindergarten, kindergarten, first and second grade. These results are similar to those of Whitehurst and colleagues (1991), who found that there were no differences at 34,44 , and 65 months of age that approached statistical significance between children with expressive language delay who received communitybased intervention services and those who did not. The same was true of the Whitehurst study subjects who received a home based intervention, although the treatment group consistently surpassed the non-treatment group in absolute terms. Similarly, this study did find a non-significant trend of consistently higher outcomes for the $\mathrm{Rx}$ group through all outcome points, particularly at second grade. The differences in mean DSS scores were $.32, .48$, and .35 respectively for the pre-kindergarten, kindergarten and first grade outcome point. At second grade, the trend of a higher Rx group DSS mean continues, but shows a greater difference of 1.33 between the groups, suggesting a possible advantage for the early intervention group in maintaining improvement in syntax and morphology at a time when academic demands for expressive language increase. 
Other Possible Contributing Factors

Subjects were placed in the Rx or No Rx group based on parent reports of intervention services before the age of four. Whether treatment was received after the age of four, which may be reflected in the longitudinal outcome data for kindergarten first and second grade, is not known. Other factors not taken into consideration for the present study, such as the length and intensity of the early intervention, the type of intervention (individual, group or home based) and the specific content of treatment, may be related to the results. Additionally, not all subjects had DSS results available for all outcome points. The failure to obtain significant differences may have been partially due to low statistical power resulting from a small sample size.

\section{Pattern of Improvement}

The Rx group mean DSS outcomes were consistently higher than the No $\mathrm{Rx}$ group outcomes at all outcome points, although it was not of statistical significance. In terms of normative data from the DSS, the tenth percentile is the cut-off for being within normal range. At the four outcome points, the group mean age and group mean DSS can be plotted as illustrated in figure 2 , to show a pattern similar to the "illusory recovery" found by Scarborough and Dobrich (1990).

At the pre-kindergarten follow-up, the $\mathrm{Rx}$ group mean lies on the tenth percentile, while the No Rx group falls somewhat below. At kindergarten, $\mathrm{Rx}$ means falls slightly below the tenth percentile, with No Rx group scores remaining lower. By looking at the pre-kindergarten and kindergarten score clustered close to the tenth percentile, it might be suggested that children who presented with SELD at the age of 
two have come close to the norm with or without early intervention. However, scores for both the Rx and No Rx groups show little improvement between the kindergarten and first grade outcome points, and fall well below the tenth percentile. The normalization of scores at the kindergarten level appears illusory because it is not maintained at the first grade level, when the demands and complexity of language increase.

Figure 2

Mean DSS for Rx and No Rx Groups at Four Outcome Points

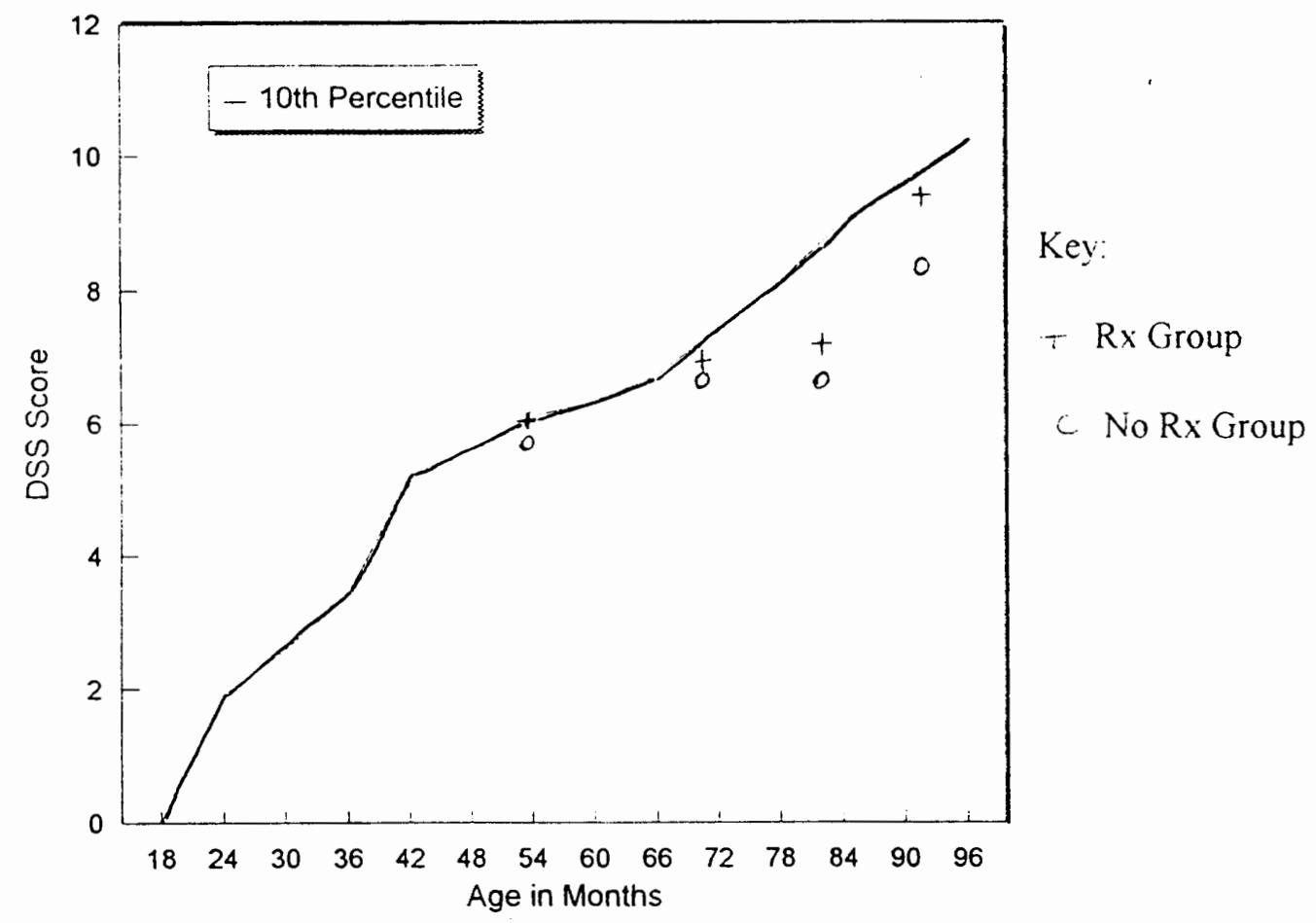

Adapted from Norms for Developmental Sentence Scoring (Lee, 1974)

Between first and second grade, the amount of improvement is greater for the $R x$ group, placing the mean close to the tenth percentile, while the No Rx group mean score shows the greatest lag behind the Rx group, and is well below the tenth percentile. For those SELD children who did not receive early intervention, expressive difficulties 
continue to show a trend of delay into second grade. A question is raised concerning the broad effects of early intervention when this non-significant trend is reviewed. Did the $\mathrm{Rx}$ group gain the ability or knowledge in early intervention to ignite their natural learning processes and allow them to continue to produce gains beyond the No $\mathrm{Rx}$ group? Initial Severity and Early Intervention

The second purpose of this study was to determine if significant differences in initial severity levels could help define the $\mathrm{Rx}$ and No Rx groups of children with SELD. Results of the t-test performed on the Expressive Communication score of the VABS at age two indicated no significant differences in severity levels of the two groups.

The subjects identified with slow expressive language development on the Language Development (LDS) at intake were assessed with a variety of other instruments at that time, including the Bayley Scales of Infant Development, Reynell Developmental Language Scale, Chapman-Miller comprehension procedure and a ten minute motherchild interaction. Results of the assessment procedures were explained to parents and referral options for early intervention were made. The findings of this study have indicated that the initial severity level, as indexed by the Expressive Communication subdomain of the VABS, was not a key factor in motivating enrollment in intervention for the child with SELD. It could be speculated that parents had a sense of overall need for intervention when they responded to recruitment for participating in the study of children who were slow to talk. Decisions to enroll children in very early intervention were most likely complex decisions, and the initial severity level as seen on the VABS may have been only one component. The answers to why some children with SELD who scored 
poorly were not enrolled in early intervention are most likely as varied as the individuals and their families.

\section{Severity and Age Range}

The severity level represented by the mean scores for the $\mathrm{Rx}$ group (13.91) was lower than the No Rx group (14.05), although the difference was not statistically significant and the null hypothesis cannot be rejected for this particular sample. The range of Expressive Communication raw scores for the $\mathrm{Rx}$ group was 11 to 17 (standard deviation of 1.78), while the range of scores for the No $\mathrm{Rx}$ group was much larger, from 7 to 20 (standard deviation of 3.11).

The chronological age of subjects also showed a range, with younger children, including the youngest subjects at 18 to 21 months of age, falling into the No Rx group (average age 23.9 months, ) compared to the $\mathrm{Rx}$ group (average age 26.9 months). It could be speculated that age might have been another factor in determining enrollment in intervention. A two sample t-test was applied to the chronological ages of the $\mathrm{Rx}$ and No $\mathrm{Rx}$ groups at intake to see if the observed difference in mean age was significant. Results showed that at the .05 level of significance, with 29 degrees of freedom, the $t$ value was 2.17 , and the $\mathrm{p}$ value, .038 , indicating that a significant difference does exist. This finding suggests that the younger ages of some of the children with SELD was a factor in the decision to not enroll in intervention, perhaps envisioning more time available to "catch up" developmentally. For older toddlers, research supports the importance of age as a factor by finding that the longer a child continues to show a delay of producing less than 50 words, the more likely they will have future long term deficits 
(Paul, 1993; Rescorla and Schwartz, 1990), supporting the need for intervention services. Findings of significantly different ages between the $\mathrm{Rx}$ and No $\mathrm{Rx}$ groups in this study supports the appropriateness of early intervention for older toddlers with persistent slow expressive language development. Parents may percieve a greater need for intervention or feel a greater concern after the age of two. Enrollment in intervention may facilitate the "boost" needed for late talkers to demonstrate expressive language ability within the average range.

\section{Amount of Needed Improvement}

In general terms, and extending the findings of the first research question, it appears that regardless of initial severity, most children will reach within the low end of the normal range of expressive language development by age five or six. The amount of change or improvement needed for those children with SELD who show greater severity of delay around the age of two is more than those children who are not as severely impaired. It would follow that early intervention would be of greatest service to the more severely delayed child, to facilitate change and assist in the development of a normal range of language production.

The information obtained from parents when the subjects were four years of age details some parameters of the intervention services received by the Rx group (see Table 3). Overall, intervention was rather short lived, averaging a duration of ten months, one week, and rather infrequent during that time, with an average of one hour and 28 minutes per week of treatment. This may have been an additional factor affecting outcomes and the failure to reject the null hypothesis for these subjects. 


\section{CHAPTER V}

\section{SUMMARY AND IMPLICATIONS}

\section{Summary}

Children who are identified with slow expressive language development (SELD) around the age of two are producing less than fifty intelligible words or no two word phrases at a time when their normally developing peers seem to be talking all the time. It is around this age that parents are concerned about the child who is slow to talk and may seek evaluation and possible early intervention. Current research suggests that some children with SELD outgrow their delay while others continue to develop long-term language difficulties. Definitive results to guide the speech language pathologist in giving recommendations concerning early intervention are not readily available in the literature, with varied theories of short term recovery but long term deficits (Scarborough and Dobrich, 1990), outcomes predicted to normalize around kindergarten with or without intervention (Whitehurst et al 1991), support for specific content in early intervention, particularly for skills beyond vocabulary development that are interrelated to expressive language, such as metalinguistics (Olswang and Bain, 1991; Paul, Laszlo and McFarland, 1992), and suggestions for a mix of intervention and monitoring for children with SELD, in step with critical learning periods and signs of readiness indicated by dynamic assessments, to facilitate improved performance and hasten development (Olswang and Bain, 1991; Weismer, et al., 1994). The design of this study 
attempted to support the recommendation of early intervention, particularly for those children with greater severity levels of expressive communication delay at the age of two.

The first purpose of this study was to determine if significant differences existed in the improvement in language production between the children with SELD who received intervention before the age of four( $\mathrm{Rx}$ group) and the children with SELD who did not receive such early intervention (No Rx group). As an efficacy study, the recorded improvement of scores were tracked over time, with outcomes indicated by the group means of the Developmental Sentence Score (DSS) procedure (Lee, 1974). The first research hypothesis was that the scores of the $\mathrm{Rx}$ group would be significantly different than the scores of the No Rx group at four points in time: pre-kindergarten, kindergarten, first and second grade. The second hypothesis was that the initial severity level of the children with SELD would show significant differences between the $\mathrm{Rx}$ and the No $\mathrm{Rx}$ groups, using the Expressive Communication sub-domain of the Vineland Adaptive Behavior Scale, (VABS), administered at age two, as the measure of severity of SELD. The subjects with SELD were part of the Portland Language Development Project, a longitudinal study. Intake was at two years, when the subjects were identified as SELD using the Language Development Survey (Rescorla, 1989), and scores of the Expressive Communication sub-domain of the VABS were used as a measure of severity of deficit. Group placement ( $\mathrm{Rx}$ and No $\mathrm{Rx}$ ) was a result of information gathered on a parent questionnaire regarding enrollment in any prior intervention services when the subjects were age four. Yearly follow-up assessments took place with numerous tests 
administered, including syntactical analysis of spontaneous language, using the DSS. For this study, DSS outcomes when the subjects were about four years old (prekindergarten), in kindergarten, first, and second grade were used.

A two tailed t-test was used to compare mean DSS scores at each of the four outcome points. This test revealed no significant differences between the $\mathrm{Rx}$ and No $\mathrm{Rx}$ groups. A two tailed t-test was also used to compare mean scores on the Expressive Communication sub-domain of the VABS at intake. This test revealed no significant differences in initial severity between the Rx and No Rx groups. In summary, the findings from this study concerning the efficacy of intervention services before the age of four and finding a relationship between initial severity and receiving intervention is inconclusive. Although there were no significant differences, failing to reject either null hypotheses, it can be noted that the Rx group did show a lower (more impaired) actual mean score on the severity instrument at the age of two, and consistently higher (more improved) actual mean scores on the DSS at all four outcome points, compared to the No Rx group. Looking at the data from a different perspective found significant differences in ages between the two groups at intake, with older toddlers falling into the Rx group, supporting the importance of age as a factor to consider when discussing options for early intervention. It is also noted that this study represented a small sample size, particularly for the kindergarten and first grade outcome points, due to missing data. Failure to reject the null hypotheses may be related to inadequate sample size . 


\section{Implications}

$\underline{\text { Research }}$

Future research is needed to help identify the characteristics and factors surrounding slow expressive language development that would predict outcomes or provide a basis for recommending or not recommending early intervention. The issue of changing and increasing demands for language use as children progress through the school years is an interesting framework for further research. What important building blocks are missing in the child with SELD that predict long term deficits?

Intervention services provided for the subjects of this study included individual and group treatment that ranged from one half hour a week to three hours a week, from one month in duration up to two years. Any amount of early intervention qualified the subjects in this study for placement in the Rx group, however the average time spent in intervention sessions per week was brief (under one and a half hours), which may have had an influence on outcome progress. No information was available regarding the content or focus of the early intervention session. Future research would be interesting if the length, type and content of intervention services received before entering kindergarten were considered individual variables to be studied in relation to outcomes and treatment efficacy. For example, does particular attention to metalinguistics, pragmatics, or narratives in early intervention services show significant improvement differences in future outcomes of language skill? Would a more intense schedule of intervention or a particular delivery model result in significant differences between $\mathrm{Rx}$ and No Rx groups? 
A statistically significant difference in age at intake was found between the $\mathrm{Rx}$ and No Rx group in this study. Reasearchers conclude that the longer a child remains delayed in expressive language development, the more likely the risk for future language impairments (Rescorla and Schwartz, 1990; Paul, 1993). It was not surprising, then, to find that the $\mathrm{Rx}$ group represented a more advanced mean age at intake. Further research could address the question of finding the lowest age at which very early intervention is appropriate and effective for future expressive language development. Is there an age limit on initiating intervention? Does a particular service delivery model or focus function with better success for specicific age groups?

Evaluating the effectiveness of early language intervention is a challenge due to the complexity of language development and necessary interrelated skills. It is difficult to isolate individual variables that are separate from natural maturation and can be considered responsible for observed outcome improvements. Fey and Cleave (1990) argue that research that attempts to evaluate intervention with isolated variables is neglecting an important function of intervention: to create broad changes in language form, content, and function that stimulate the child's existing language learning process and allow those processes to function optimally. This study showed an non-significant trend for consistently higher DSS outcomes for the Rx group, particularly at the second grade level. To support this trend, research is needed to document that a child with SELD becomes generally more able to learn and gain in language, as well as grow in social, emotional and academic performance, through knowledge acquired in early intervention. 
The DSS measure used in this study indicates primarily the syntactical complexity of spontaneous speech. Dynamic assessments might be used in future reasearch to indicate broader positive results of intervention services.

\section{Clinical}

The results of this study would suggest that early intervention for children with SELD would not be a high priority before the age of four. The inability to reject the null hypothesis may have been due to the small sample size, and further research with larger subject groups is needed to determine if the results of this study would apply to most children with SELD when considering early intervention. Subjects in this study represented a primarily middle class socioeconomic group, allowing findings to be related only to children with a similar socioeconomic background.

Significant mean age differences found between subject groups indicates that children with SELD who were somewhat older toddlers at intake were then reported to receive some early intervention before the age of four. Rescorla (1989) developed the LDS to identify expressive language delay for children as young as 18 months. In this study, following the identification of an expressive delay using the LDS, the SELD children who were as young as 18 and 21 months old did not receive treatment (average age for the No $\mathrm{Rx}$ group was 23.9 months), while the average age of the treatment group was 26.9 months. Research supports age as a risk factor for continued deficits (Paul, 1993; Rescorla and Schwartz, 1990), indicating the usefulness of intervention for older toddlers with SELD.

Although receiving individual and group intervention did not result in 
significantly different scores at any of the outcome points for this study, other research has found early intervention effective. The question remains regarding the importance of early services (Whitehurst, et al., 1991). The evaluation of children who are slow to talk needs to be a complete look at such risk factors as medical history, social and pragmatic communication functioning, and should include knowledge of predictive factors such as age, gender, and range of impaired language functions (Paul, 1993; Bishop and Edmundson, 1987). Attention to developmental readiness (Long and Olswang, 1996) and times of natural vocabulary bursts can add to the understanding of intervention needs for children with slow expressive language development.

Language assessments are used to determine if an impairment exists, and may also give information about a child's readiness for language growth and change. Olswang and Bain (1996) indicate that dynamic assessments can best predict the possiblity of immediate language growth. Static assessment tools, such as standardized tests, focus on the current level of performance, while dynamic assessment looks at the potential for a child to use adult prompts and cues when faced with an unmastered task. Looking for the child's optimal level of achievement through dynamic assessment can be time consuming, but is shown by Olswang and Bain to be a good indicator of which children are ready to learn and best benefit from intervention.

Results of a dynamic assessment, along with various options of monitoring, indirect consultation or direct intervention need to be shared with parents of children with SELD. A rationale for facilitative early intervention may be appropriate, along with parent education regarding aspects of language development and concurrent 
psychosocial development. The content of treatment models needs to reflect the knowledge that SELD may manifest with a vocabulary deficit at a very early age, but may change to phonological, syntactical, articulation or narrative production deficits as the child attempts to "catch up" with normally developing peers.

Reliable and objective measurements for specific target areas of language impairment are also helpful when attempting to show efficacy of early intervention. The challenge is to show that improvements in outcome are not solely the result of variables such as maturation or a physical or environmental change. Progress, plateau, or regression should be noted in relationship to "breaks" in treatment. Assessment in conversational contexts and those involving family or others who are important in the child's environment help to make the measures "ecologically valid" (Fey and Cleave, 1990)

This study would seem to indicate that advice to parents of very young toddlers (under 24 months) with SELD would support a "don't worry" attitude, with options of intervention services if time and interest are indicated by parents. For older toddlers, if a dynamic assessment indicates a readiness to change, parents can be assured that language growth will most likely occur, with the options of early intervention as a facilitation for faster change, or, again, simply allowing maturation and experience to stumulate language growth.

SELD may, however, undergo some change in deficit manifestation as the child enters school and the language demands increase in complexity. Gains from various levels of severity at intake showed a possible "illusory recovery" similar to findings of 
Scarborough and Dobrich (1990). Children with SELD appeared to reach within average range of DSS scores by kindergarten, but scored below average again at first and second grade. Parents need to be aware that children with SELD at the age of two may benefit from monitoring progress as they develop, with further assessment, and possible intervention, if future language deficits are seen in response to increased expectations for complex verbal expression, writing and reading.

Clinicians need to be aware of the characteristics of toddlers with SELD and know the risk factors that herald possible continuing deficits. They need to utilize sound principles of data collection and assessment, and they need an understanding of intervention models and appropriate treatment content for very early intervention. Clinicians may then be able to demonstrate the effectiveness of intervention and feel confident in making recommendations to parents of children with slow expressive language development. 


\section{REFERENCES}

Aram, D., Ekelman, B., \& Nation, J. (1984). Preschoolers with language disorders: 10 years later. Journal of Speech and Hearing Research, 27, 232-244.

Bayley, N. (1969). Scales of infant development. New York: Psychological Corporation.

Bishop, D., \& Edmundson, A. (1987). Language-impaired 4-year-olds:

Distinguishing transient from persistent impairment. Journal of Speech and Hearing Disorders, 52, 156-173.

Cole, K., \& Dale, P. (1988). Direct language instruction and interactive language instruction with language delayed preschool children: A comparison study. Journal of Speech and Hearing Research, 29, 206-217.

Catts, H. (1993). The relationship between speech-language impairments and reading disabilities. Journal of Speech and Hearing Research, 36, 948-958.

Fenson, L., Dale,P., Reznick, S., Thal, D., Bates, E., Hartung, J., Patrick S., \& Reilly, J. (1991).Techinical manual for the MacArthur Communicative Development Inventories. San Diego: San Diego State University.

Fey, M. and Cleve, P. (1990). Early language intervention. Seminars in Speech and Language, $11,165-182$.

Gottlieb, G. (1976) Studies on the development of behavior and the nervous system:Neural and behavioral specificity. New York: Academic Press.

Fishel, J., Whitehurst, G., Caulfield, M., \& DeBaryshe, B. (1989). Language 
growth in children with expressive language delay. Pediatrics, 82, 218-227.

Lee, L. (1974). Developmental sentence analysis. Evanston, IL: Northwestern University Press.

Long, S. and Olswang, L. (1996). Readiness and patterns of growth in children with SELI. American Journal of Speech-Language Pathology, 5 , 79-85.

Miller, J. (1981) Assessing language production in children. Baltimore, MD: University Park Press.

Myers, J., \& Bean, L. (1968). A decade later: A follow-up of social class and mental illness. NY: Wiley and Sons.

Olswang, L., \& Bain, B. (1991). Intervention issues for toddlers with specific language impairments. Topics in Language Disorders, 11(4), 1-13.

Olswang, L., \& Bain, B. (1994). Data collection: Monitoring children's treatment progress. American Journal of Speech Language Pathology, $4,55-65$.

Olswang, L., \& Bain, B. (1996). Assessment information for predicting upcoming change in language production. Journal of Speech and Hearing Research, 39, 414-423.

Paul, R. (1991 a). Assessing communication skills in toddlers. Clinical Communication Disorders, 1. (2), 7-23.

Paul, R. (1991 b). Profiles of toddlers with slow expressive language development. Topics in Language Disorders, 11(4), 1-13.

Paul, R. (1992). Specific developmental language disorders. In P.J. Wilner (Ed.), Psychiatry (chapter 49). Philadelphia: J.B. Lippencott Company.

Paul, R. (1993) Patterns of development in late talkers: Preschool years. Journal 
of Childhood Communiction Disorders, 15 7-14.

Paul, R. (1995). Language disorders from infancy through adolescence. St. Louis: Mosby-Year Book.

Paul, R., Lazlo, C., \& McFarland, L. (1992, November). Emergent literacy skills in late talkers. Mini-seminar presented at the National Convention of the American Speech-Language and Hearing Association, San Antonio, Texas.

Paul, R., \& Smith, R. (1993). Narrative skills in 4-year-olds with normal, impaired, and late-developing language. Journal of Speech and Hearing Research, 36 , $592-598$.

Paul, R., Spangle-Looney, S., \& Dahm, P. (1991). Communication and socialization skills at ages 2 and 3 in "late talking" young children. Journal of Speech and Hearing Research, 34, 604-612.

Rescorla, L. (1989). The language development survey: A screening tool for delayed language in toddlers. Journal of Speech and Hearing Disorders, 54, 587-599.

Rescorla, L., \& Schwartz, E. (1990). Outcome of toddlers with specific expressive language delay. Applied Psycholinguistics, 11, 393-407.

Scarborough, H., \& Dobrich, W. (1990). Development of children with early language delay. Journal of Speech and Hearing Research, 30, 70-83.

Soriano, D., Paul, R., \& Cohen, D. (1988). Report on adaptive behavioral outcomes in adolescents with developmental language disorders. NSSLHA Journal, 16 , 106-114.

Sparrow, S., Balla, D., \& Cicchetti, D. (1984). Vineland adaptive behavior scales. 
Circle Pines MN: American GuidanceService.

Stoel-Gammon, C. (1987). Phonological skills of two-year olds. Language, Speech, and Hearing Services in Schools, 18 , 323-329.

Terman, L., \& Merril, M. (1960) Stanford-Binet intelligence scale. Boston: Houghton Mifflin.

Thal, D. (1991). Language and cognition in normal and late-talking toddlers. Topics in Language Disorders, $11,33-42$.

Thal, D. \& Tobias, S. (1994) Relationships between language and gesture in normally developing and late-talking toddlers. Journal of Speech and Hearing Research, 37. $157-170$.

Thal, D., Tobias, S., \& Morrison, D. (1991). Language and gesture in late talkers: A 1-year follow-up. Journal of Speech and Hearing Research, 34, 604-612.

Weismer, S., Murray-Branch, J., \& Miller, J. (1993) Comparison of two methods for promoting productive vocabulary in late talkers. Journal of Speech and Hearing Research, 36, 1037-1050.

Weismer, S., Murray-Branch, J., \& Miller, J. (1994). A prospective longitudinal study of language development in late talkers. Journal of Speech and Hearing Research, 37. $852-868$.

Whitehurst, G., Fishchel, J., Lonigan, C., Valdez-Menchaca, V., Arnold, D., \& Smith, M. (1991). Treatment of early expressive language delay: If, when and how. Topics in Language Disorders, 11(4), 55-68. 
APPENDIX A

RECRUITMENT NEWSPAPER ARTICLE

Source: The Oregonian, Portland Oregon 


\section{Toddlers with delayed speech sought}

A Portand State University researcher is looking for otherwise normal toddlers who begin talking late to serve as subjects in a study of delayed speech and its connection, if any, to later language problems.

Rhea Paul, a PSU assistant professor of speech communication, said the reasons for delayed speech in "late-blooming" young children and the early identification of toddlers who later will suffer chronic language delay had not been well-investigated, although perhaps 10 percent of American children may fall into those categories.

Paul is interested in studying children berween the ages of 18 and 30 months in the Portand-Vancouver area who can say only five or fewer words, instead of the 50 or so most children can speak by that age. She hopes to monitor their progress in speech development for two to five years, using such tools as speech tests and videotaped play sessions with their parents, to determine whether the children are indeed late-bloomers or whether their lack of early communication skills signals the start of severe speech and language delays.

Early identification of such children may allow early intervention and prevent furure speech deficits, she said.

Paul's research is funded by the Fred Meyer Charitable Trust, the American Speech, Language and Hearing Foundation, and PSU. Parents who are interested in allowing their children to participate may contact Paul through the PSU Department of Speech. 


\section{APPENDIX B}

HUMAN SUBJECTS APPROVAL

Office of Graduate Studies and Research

Portland State University 
OFFICE OF GRADUATE STUDIES AND RESEARCH

Research and Sponsored Projects

DATE: $\quad$ October 31,1995

TO: $\quad$ Kathleen Belflore $\quad$ SSN\# 356-42-6805

FROM: for Laurie Skokan, Chair, HSRRC, 1995-96

RE: $\quad$ HSRRC Waived Review of Your Application titled A Study Of Intervention History Of Late Talkers And Outcomes At Kindergarten And Second Grade"

Your proposal is exempt from further HSRRC review, and you may proceed with the study.

Even with the exemption above, it was necessary by University policy for you to notify this Committee of the Proposed research and we appreciate your timely attention to this matter. If you inake changes in your research protucol, the Committee must be notified. This approval is valid for one year from date of issue.

c: $\quad$ Maureen Orr Eldred
Rhea Paul, Project Advisor

waiver.mem 


\section{APPENDIX C}

\section{LANGUAGE DEVELOPMENT SURVEY:}

WORD LIST

Source: Rescorla, L. (1989) 


\section{Language Development Survey}

Please check o!l each word that your child says SPONTANEOUSLY inoe lust imitates or undcri:ands" li's okay 10 coune "ords that aresie pronounced clearly or are in "baby calk" I"baba" lor bot:!

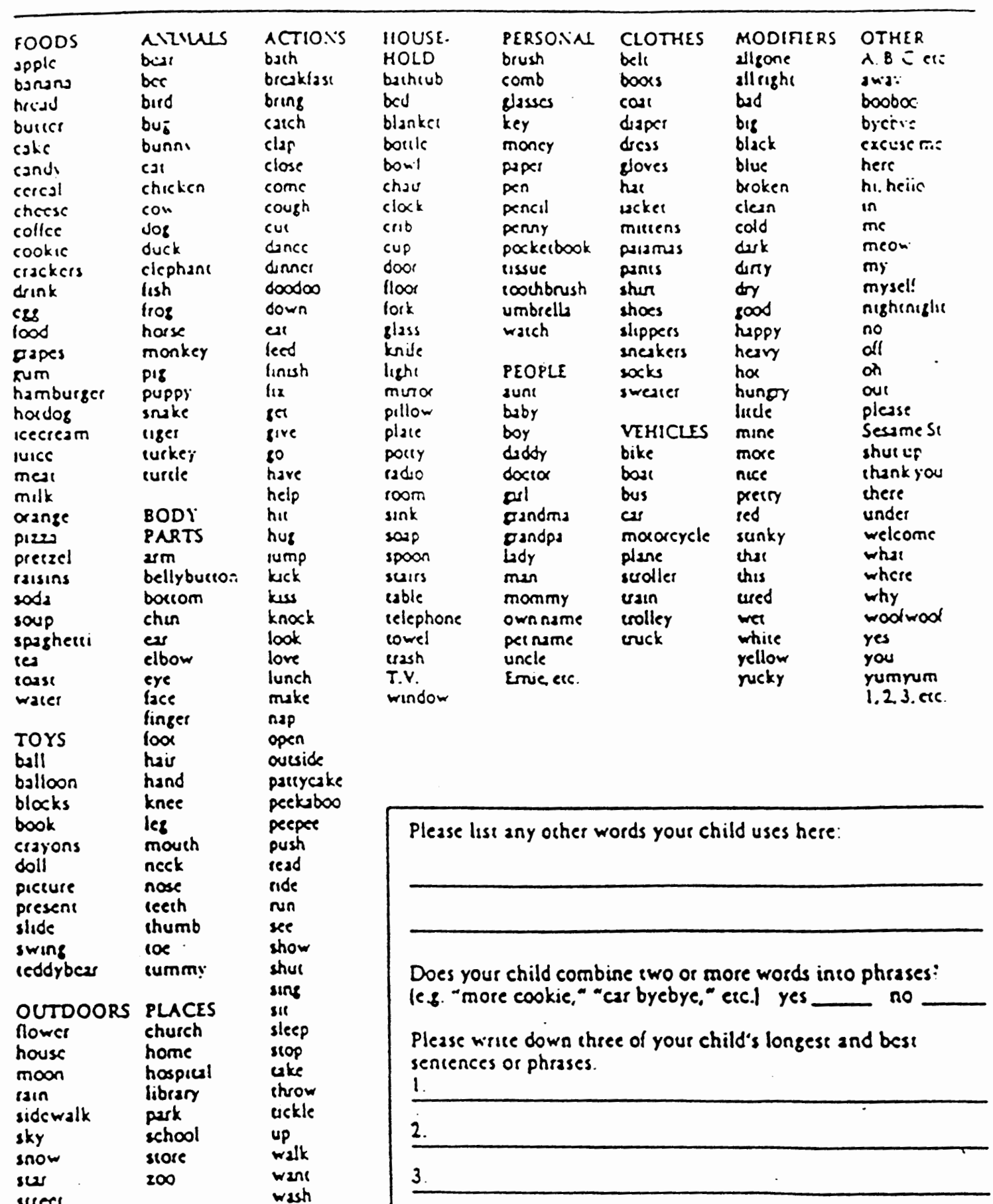




\section{APPENDIX D}

\section{ASSESSMENT INSTRUMENTS:}

BASELINE (AGE 2)

Source:

Paul, R. (1991). Assessing communication skills

in toddlers. Clinical Communication Disorders, 1, 7-23. 
ASSESSMENT INSTRUMENTS: EASELI:EEVALUATIONS (AGE 2)

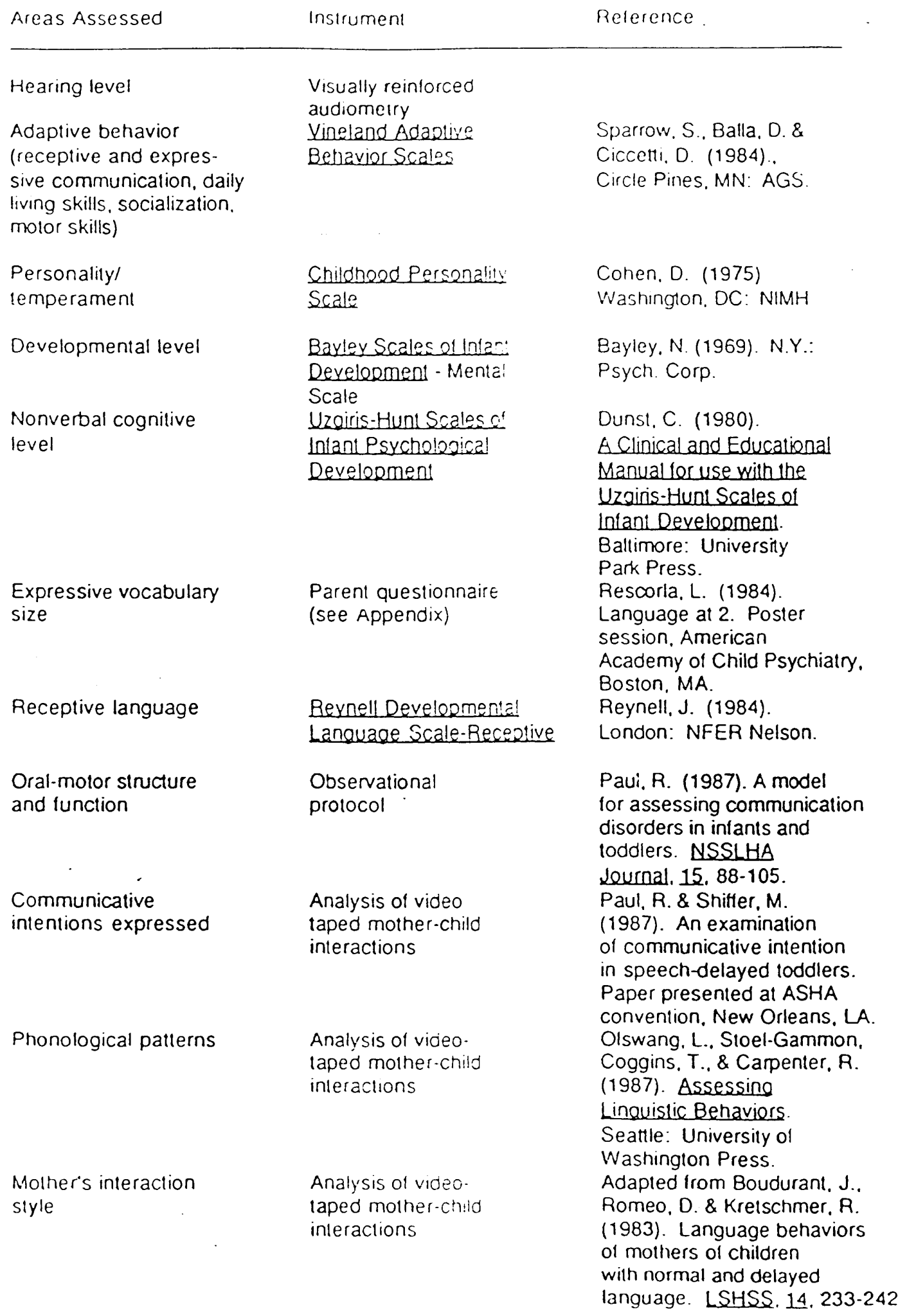




\section{APPENDIX E}

DEVELOPMENTAL SENTENCE SCORE:

NORMS

Source: Lee, L. (1974) 


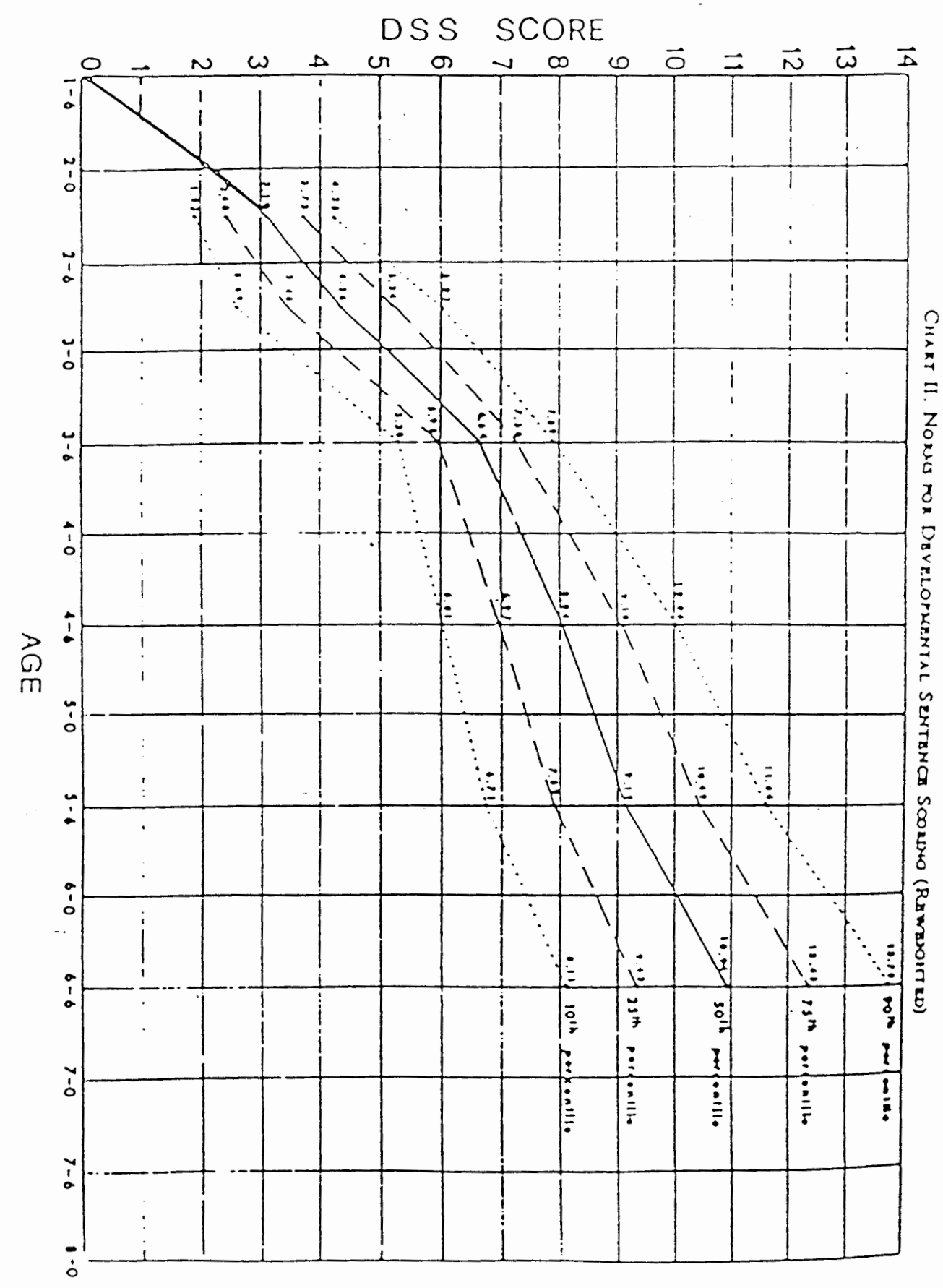


APPENDIX F

DEVELOPMENTAL SENTENCE SCORES FOR

Rx AND NO Rx GROUPS AT PRE-KINDERGARTEN (AGE FOUR), KINDERGARTEN, FIRST AND SECOND GRADE 
DSS Outcomes of SELD Children Who Received Early Intevention

\begin{tabular}{|c|c|c|c|c|c|c|c|c|c|}
\hline $\begin{array}{l}\text { Subject } \\
\text { Number }\end{array}$ & Gender & $\begin{array}{c}\text { C.A } \\
\text { in Months }\end{array}$ & $\begin{array}{c}\text { Pre-kindergarten } \\
\text { DSS }\end{array}$ & $\begin{array}{c}\text { C.A } \\
\text { in Months }\end{array}$ & $\begin{array}{c}\text { Kindergarten } \\
\text { DSS } \\
\end{array}$ & $\begin{array}{c}\text { C.A } \\
\text { in Months }\end{array}$ & $\begin{array}{c}\text { 1st Grade } \\
\text { DSS }\end{array}$ & $\begin{array}{c}\text { C.A } \\
\text { in Months }\end{array}$ & $\begin{array}{c}\text { 2nd Grade } \\
\text { DSS }\end{array}$ \\
\hline 007 & $M$ & 50 & 6.44 & 73 & 6.74 & 81 & 9.07 & 90 & 10.26 \\
\hline 019 & $\mathrm{~F}$ & 61 & 6.78 & 71 & 8.11 & 81 & 6.98 & 96 & 6.91 \\
\hline 085 & $M$ & 54 & 5.70 & 71 & 5.82 & 80 & 7.28 & 88 & 10.08 \\
\hline 090 & $M$ & 49 & 5.23 & - & - & - & - & 95 & 13.98 \\
\hline 091 & M & 52 & 3.64 & - & - & - & - & 94 & 8.6 \\
\hline 093 & $M$ & 49 & 3.26 & 70 & $6 . \epsilon \varepsilon$ & 79 & 4.53 & 91 & 6.84 \\
\hline 100 & $M$ & 57 & 7.40 & 72 & 6.23 & 81 & 6.26 & 89 & 11.96 \\
\hline 102 & $M$ & 50 & 8.08 & 73 & $7.5 \varepsilon$ & 85 & 7.58 & 96 & 9.84 \\
\hline 103 & $M$ & 48 & 7.40 & 71 & 7.40 & 82 & 7.40 & 90 & 10.54 \\
\hline 111 & $\mathrm{~F}$ & 52 & 5.70 & 71 & 7.44 & 80 & 6.34 & 85 & 9.84 \\
\hline 119 & M & 53 & 5.26 & 70 & $6 . \varepsilon \hat{\varepsilon}$ & 91 & 7.92 & 102 & 10.14 \\
\hline \multicolumn{2}{|l|}{ Mean DSS } & & 5.90 & & 7.03 & & 7.04 & & 9.91 \\
\hline \multicolumn{2}{|c|}{ Standard Deviation } & & 1.46 & & 2.79 & & 2.92 & & 1.94 \\
\hline \multicolumn{2}{|c|}{ Mean Age in Months } & 52 & & 71 & & $82^{\circ}$ & & 92 & \\
\hline Total Numb & of Subjects & 11 & & & & & & & \\
\hline Male & & 9 & & & & & & & \\
\hline Female & & 2 & & & & & & & \\
\hline
\end{tabular}

DSS Outcomes for SELD Children Who Did Not Receive Early Intervention

\begin{tabular}{|c|c|c|c|c|c|c|c|c|c|}
\hline $\begin{array}{c}\text { File } \\
\text { Number }\end{array}$ & Gender & $\begin{array}{c}\text { C.A. } \\
\text { in Months }\end{array}$ & $\begin{array}{c}\text { Pre-kindergarten } \\
\text { DSS }\end{array}$ & $\begin{array}{c}\text { C.A. } \\
\text { in Months }\end{array}$ & $\begin{array}{c}\text { Kindergarten } \\
\text { DSS }\end{array}$ & $\begin{array}{c}\text { C.A } \\
\text { in Months }\end{array}$ & $\begin{array}{c}\text { 1st Grade } \\
\text { DSS }\end{array}$ & $\begin{array}{c}\text { C.A } \\
\text { in Months }\end{array}$ & $\begin{array}{c}\text { 2nd Grade } \\
\text { DSS }\end{array}$ \\
\hline 006 & $M$ & 49 & 6.60 & 73 & 5.94 & 81 & 7.28 & 90 & 10.98 \\
\hline 012 & $\mathrm{~F}$ & 49 & 5.20 & 70 & 7.44 & 79 & 7.14 & 88 & 8.52 \\
\hline 029 & $F$ & 50 & 4.24 & 73 & 6.62 & 82 & 5.38 & 92 & 9.4 \\
\hline 041 & M & 50 & 7.96 & 71 & 9.64 & 80 & 7.82 & 86 & 9.56 \\
\hline 053 & $M$ & 52 & 8.18 & 75 & 9.02 & - & - & - & - \\
\hline 057 & $\mathrm{~F}$ & 50 & 8.22 & 70 & 6.82 & • & 7.88 & 88 & 9.94 \\
\hline 084 & $M$ & 50 & 8.50 & * & - & 77 & 9.17 & 83 & 10.06 \\
\hline 086 & M & 49 & 7.02 & 68 & 6.87 & 85 & 7.02 & 94 & 8.22 \\
\hline 087 & M & 48 & 7.90 & 71 & 8.96 & 79 & 8.74 & 89 & 8.66 \\
\hline 092 & M & 55 & 4.10 & 70 & 7.38 & 80 & 8.32 & 97 & 12.24 \\
\hline 094 & M & 52 & 2.91 & 76 & 6.06 & 83 & 5.00 & 95 & 9.88 \\
\hline 097 & $M$ & 50 & 3.48 & 70 & 4.46 & 76 & 6.72 & 100 & 6.96 \\
\hline 098 & $M$ & 50 & 6.90 & 69 & 6.82 & 77 & 6.42 & 98 & 8.84 \\
\hline 101 & $\mathrm{~F}$ & 48 & 6.50 & - & * & 81 & 6.85 & 86 & 7.68 \\
\hline 105 & $M$ & 53 & 6.68 & 70 & 9.06 & 81 & 10.26 & 84 & 10.24 \\
\hline 107 & $M$ & 49 & 4.68 & 69 & 8.50 & 85 & 8.62 & 94 & 9.9 \\
\hline 109 & $M$ & 50 & 8.95 & 69 & 6.78 & 85 & 7.02 & 93 & 9.14 \\
\hline 114 & $M$ & 49 & 6.74 & 69 & 11.16 & 83 & 7.94 & 98 & 12.04 \\
\hline 116 & $M$ & 59 & 5.60 & 76 & 6.50 & - & $*$ & - & * \\
\hline 142 & $F$ & 49 & 4.56 & 68 & 6.30 & 82 & 6.66 & 92 & 9.32 \\
\hline \multicolumn{2}{|l|}{ Mean DSS } & & 5.58 & & 6.55 & & 6.69 & & 8.58 \\
\hline \multicolumn{2}{|c|}{ Standard Deviation } & & 2.51 & & 3.28 & & 2.92 & & 3.64 \\
\hline \multicolumn{2}{|c|}{ Mean Age in Months } & 51 & & 71 & & 81 & & 92 & \\
\hline Total Numb & of Subjects & 20 & & & & & & & \\
\hline Male & & 15 & & & & & & & \\
\hline Female & & 5 & & & & & & & \\
\hline
\end{tabular}


APPENDDX G

EXPRESSIVE COMMUNICATION SCORES OF THE

VINELAND ADAPTIVE BEHAVIOR SCALES ADMINISTERED AT

AGE TWO FOR Rx AND NO Rx GROUPS 
Vineland Scores at Intake for Late Talkers Who Received Early Intervention

\begin{tabular}{ccc}
\hline $\begin{array}{c}\text { Subject } \\
\text { Number }\end{array}$ & $\begin{array}{c}\text { C.A. } \\
\text { in Months }\end{array}$ & $\begin{array}{c}\text { Expressive Communication } \\
\text { Score }\end{array}$ \\
\hline 007 & 23 & 15 \\
019 & 32 & 17 \\
085 & 28 & 12 \\
090 & 28 & 11 \\
091 & 27 & 16 \\
093 & 24 & 15 \\
102 & 30 & 15 \\
103 & 25 & 14 \\
111 & 24 & 13 \\
115 & 29 & 13 \\
119 & 26 & 12 \\
Mean Score & & 13.91 \\
Standard Deviation & & 1.78 \\
Mean Age & 27 &
\end{tabular}

Vineland Scores at Intake for Late Talkers Who Did Not Receive Early Intervention

\begin{tabular}{rcc}
\hline Subject & $\begin{array}{c}\text { C.A. } \\
\text { in Months }\end{array}$ & $\begin{array}{c}\text { Expressive Communication } \\
\text { Sumber }\end{array}$ \\
\hline 006 & 23 & 12 \\
012 & 22 & 20 \\
029 & 26 & 12 \\
041 & 21 & 16 \\
052 & 18 & 7 \\
053 & 28 & 15 \\
057 & 20 & 12 \\
086 & 20 & 15 \\
087 & 25 & 14 \\
092 & 33 & 14 \\
094 & 31 & 17 \\
097 & 22 & 15 \\
098 & 19 & 13 \\
101 & 25 & 22 \\
105 & 24 & 13 \\
107 & 22 & 13 \\
109 & 21 & 12 \\
114 & 24 & 14 \\
116 & 31 & 14 \\
142 & 22 & 11 \\
Mean Score & & 14.05 \\
Meandard Deviation & & 3.11 \\
\hline Sge & 24 &
\end{tabular}

